See discussions, stats, and author profiles for this publication at: https://www.researchgate.net/publication/348434152

\title{
A numerical model to simulate the dynamic performance of Breathing Walls
}

Article in Journal of Building Performance Simulation · March 2021

DOI: 10.1080/19401493.2020.1868578

CITATIONS

0

3 authors:

F. Andrea Alongi

Politecnico di Milano

9 PUBLICATIONS 50 CITATIONS

SEE PROFILE

Livio Mazzarella

Politecnico di Milano

44 PUBLICATIONS 437 CITATIONS

SEE PROFILE

Some of the authors of this publication are also working on these related projects:

building energy performance assessorato And improvement View project

EcoZoo View project
12

Adriana Angelotti

Politecnico di Milano

54 PUBLICATIONS 781 CITATIONS

SEE PROFILE 
This is the original manuscript of the article:

A.Alongi, A.Angelotti, L.Mazzarella, A numerical model to simulate the dynamic performance of Breathing Walls,

published by Taylor \& Francis in Journal of Building Performance Simulation on January $10^{\text {th }} 2021$.

To cite this article:

Andrea Alongi, Adriana Angelotti, Livio Mazzarella (2021) A numerical model to simulate the dynamic performance of Breathing Walls, Journal of Building Performance Simulation, 14:2, 155-180, DOI:

10.1080/19401493.2020.1868578

For the final version, please go to:

https://www.tandfonline.com/doi/full/10.1080/19401493.2020.1868578

50 free online copies of the article are available at:

https://www.tandfonline.com/eprint/VTNQXWUQTZHAIHT9N5IA/full?target=10.1080/19401493.2020.186

8578

(Please, use this option only if you do not have access to the Journal already) 


\title{
A numerical model to simulate the dynamic performance of Breathing Walls
}

\author{
Andrea Alongi ${ }^{1 *}$, Adriana Angelotti ${ }^{1}$, Livio Mazzarella ${ }^{1}$ \\ ${ }^{1}$ Politecnico di Milano, Milano, Italy
}

\begin{abstract}
A one-dimensional Finite Difference Model for Breathing Wall components under time dependent Dirichlet boundary conditions is presented. The algorithm undergoes a comprehensive validation against a dynamic analytical model, under either sinusoidal and generically periodic boundary conditions, adopting different airflow velocities and in relation to capacitive and resistive materials alternatively.

It is found that the accurate prediction of the temperature profile inside the wall is influenced primarily by the timestep, whose optimal value can be identified through a preliminary frequency analysis of the boundary conditions. Moreover, for a better prediction of the surface heat flow density, and especially in insulating materials, refining the space grid below $1 \mathrm{~mm}$ is recommended, as well as the adoption of a 3point numerical scheme.

The numerical model is finally tested against experimental data on a porous concrete wall, showing that numerical errors may compare to other sources of uncertainties, regarding materials properties and boundary conditions.
\end{abstract}

\section{Keywords}

breathing wall; dynamic insulation; numerical model; validation; discretization; building energy simulation.

\section{Introduction}

Breathing Wall is a building envelope technology based on air permeable layers linked to the ventilation system and crossed by a desired airflow, required to meet the airchange needed for a given indoor environment. Hence, the energy performance of external walls and roofs can be controlled and tuned acting on the airflow velocity: they feature a tunable thermal transmittance (Taylor and Imbabi, 1998; Alongi et al., 2017a; Alongi et al., 2017b) performing as a kind of Dynamic Insulation system (Rupp and Krarti, 2019). Moreover, they are able to perform as heat exchangers (Taylor et al., 1996; Taylor and Imbabi,1998; Imbabi, 2006; Craig and Grinham, 2017, Alongi et al., 2019) and filters (Taylor et al., 1999; Imbabi, 2004).

In the past, this technology was mostly investigated in steady state conditions with air moving inward and heat flux moving outward (namely, contra flux condition), since this working regime is better suited for the cold climates of the northern Countries where Breathing Wall technology has been initially studied (Wallenten 1995). Analyses have been performed both numerically (Imbabi, 2012; Gan, 2000) and experimentally (Dimoudi, 2004; Imbabi, 2006; Di Giuseppe, 2015). The analytical model that predicts the behavior of Breathing Walls in steady state conditions, originally presented by Taylor et al. (Taylor et al., 1996), has been experimentally validated by the Authors (Alongi et al., 2017a; Alongi et al., 2017b) on a small sample of no-fines concrete (Wong, 2007).

As far as unsteady conditions are concerned, an analytical model for steady periodic third type conditions can be found in literature (Krarti, 1994). This model has been reconsidered by the Authors for Dirichlet boundary conditions, and the new set of equations for temperature distribution and conductive heat flux density have been derived and experimentally validated under sinusoidal conditions (Alongi et al., 2020). Moreover, from the experimental standpoint, the performance of Breathing Wall components in relations to the airflow velocity has been investigated under real climatic conditions, both through test cells (Baker, 2003; Yaegashi et al., 2015) and larger scale buildings (Brunsell, 1996; Imbabi et al., 2008).

\footnotetext{
${ }^{*}$ Corresponding author

tel.: +3902 23993867

e-mail: andrea.alongi@polimi.it
} 
Breathing Wall technology can be viewed as a promising technology in mitigating overall energy needs in buildings (Elsarrag, 2012; Ascione, 2017). However, in order to analyze the energy performance of a Breathing Wall in a building subjected to outside weather and internal gains, along with the effects of different control strategies for airflow velocity and direction, a way to describe any time dependent regime is necessary, possibly coupled to Building Energy Simulation (BES) tools. One of the first attempt described in literature is the work by Samuel et al. (Samuel et al., 2003), where the Breathing Wall part of the building envelope is fictitiously represented by a sequence of appropriately defined zones. This simplified approach is validated against the steady state analytical model and shows good agreement both in temperature distribution (within 1\%) and predicted heat flux (within $8 \%$ ) at low airflow velocity (maximum around $0.002 \mathrm{~m} / \mathrm{s}$ ). Another work from literature describes a building simulation tool that deals with envelope components using the Finite Volume Method and the explicit time discretization (Kalagasidis et al., 2008), and is able to take into consideration the convective transport of heat and moisture across walls and roofs due to pressure gradients. The same numerical scheme is used in another paper (Steeman et al., 2010) to model building envelope components, possibly crossed by airflows. Moreover, this work provides a technique to couple the walls numerical model to the building simulation tool integrated in TRNSYS (TRNbuild and type 56).

In literature, it is also possible to find works mainly focused on the Breathing Wall component stand-alone simulation. An example is provided by the work of Ascione et al. (Ascione et al., 2015), where a onedimensional Finite Difference model based on the Crank-Nicholson approach is presented. In that paper, the validation process is performed using both the steady state Taylor model and a commercial FEM software for the transient conditions; and the virtual wall is then coupled to a self-developed room model to test the opportunity for nocturnal free cooling. The Authors apply the model to a cellulose $20 \mathrm{~cm}$ thick wall, finding that 100 spatial nodes and a time step of 15 minutes are a good compromise between accuracy and computational cost. Another numerical model is presented in (Wang et al., 2018): this work deals with Exhaust Air Insulation, a particular kind of Breathing Wall in which airflow moves only from indoor to outdoor. The time implicit Finite Difference algorithm presented is applied to a multilayer wall composed of porous insulation materials and validated through direct comparison of measured and simulated surface and cavity temperatures. The time step adopted is 1 minute, but no details about the spatial grid size are provided. Finally, a work more broadly focused on Dynamic Insulation components (Park et al., 2015) studies the potential energy savings achievable through these technologies for apartment units and simulates the building envelope using a 3R2C thermal network, modified to have a virtual node at wall surfaces exposed to surroundings.

From all the mentioned papers, it appears that several numerical models for BW (Breathing Wall) can be found in literature, although a thorough analysis on the impact of the time and space discretization adopted, also in relation to the kind of porous materials implemented in the BW, to the airflow velocity and to the variability of the boundary conditions, is presently lacking. In this work, a full implicit one-dimensional unsteady Finite Difference Model for Breathing Wall technologies is adopted. A comprehensive validation is performed via comparison of numerically calculated data to analytically calculated ones, in order to assess the effectiveness of the model in depicting the temperature distribution across the domain and the heat flux densities at the boundaries. These quantities are relevant for two reasons: first, as a starting point for the future development of a more complete heat and moisture transfer model; second, as a tool to support an optimized design of BW components. At the stage, due to the features of the analytical models adopted as references, constant thermophysical properties are considered. However, a future version of the model might also include non-linearities related to temperature dependent material properties and uncertainties due to the production process, possibly implementing a technique similar to the one presented in (Gradeci et al., 2018). This validation process is also aimed at evaluating the numerical model sensitivity to discretization parameters, in relation to airflow velocity, material properties and boundary conditions fluctuation trend. From this analysis, some criteria and guidelines are derived for optimizing the parameters of the numerical model in the framework of BES. A final investigation of the model is then performed through direct comparison to experimental measurements, putting numerical errors in the more general context of experimental and materials uncertainties. 


\section{Methods}

The first step of the work is the definition of the governing equations for the unsteady heat transfer problem in Breathing Walls, along with the derivation of the full implicit one-dimensional unsteady Finite Difference Model. Then, the validation process and the performance assessment are articulated in three main phases.

Table 1: phases of the validation and performance assessment of the numerical model

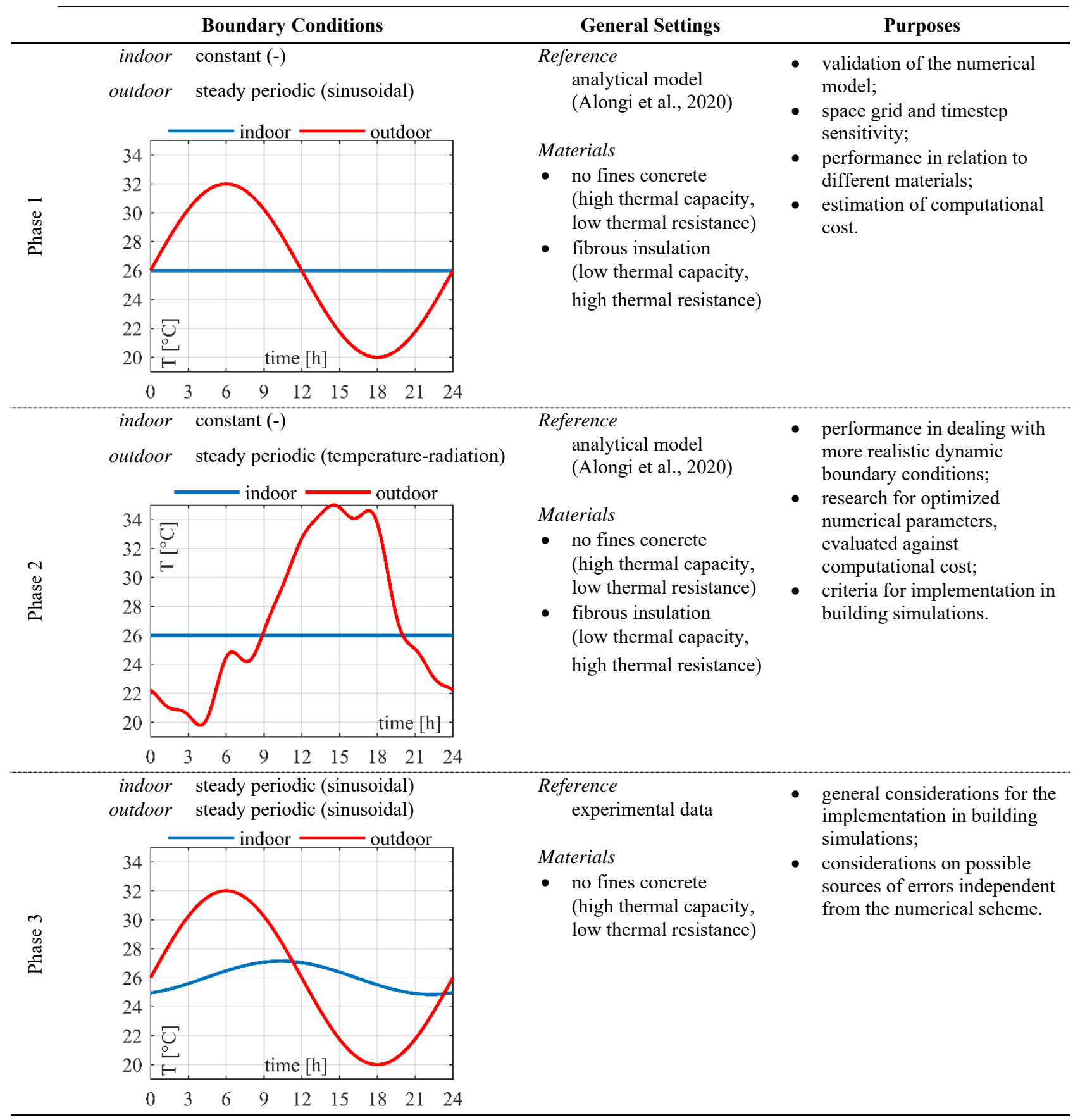

The first phase is based on the comparison between numerical and analytical data, both calculated considering a capacitive (no fines concrete) and a resistive (mineral wool) material alternatively, and imposing a constant temperature value on the indoor surface and a sinusoidal variation on the outdoor one. Temperature distribution across the sample and heat flux density on one face are collected at six airflow conditions for the numerical and the analytical (Alongi et al., 2020) models and compared. This phase is used to assess the overall performance of the numerical model and its sensitivity to space grid and timestep size.

The second phase is similar to the first one as far as materials and airflow velocity conditions are concerned. In this case, however, boundary conditions are defined by imposing a constant temperature on the indoor surface and a mixed temperature-radiation condition on the outdoor surface, which is modelled as a multi- 
harmonic superposition achieved using the Fourier series decomposition. The results are compared to the corresponding ones obtained using the analytical model by (Alongi et al., 2020). By assuming the radiation incident on a vertical North surface in summer at the latitude of Milan (Italy), the resulting boundary condition provides a greater variability than the one considered in the first phase. The aim of this phase is to test the algorithm against complicated boundary conditions that better replicate the climatic data used in building performance simulations end to identify criteria for the definition of optimal discretization parameters.

The third and last phase is based on the comparison between numerical and experimental data: a single layer sample made of no fines concrete is tested in a laboratory facility by imposing a sinusoidal steady periodic operative temperature on one side and a steady state condition on the other, leading to two surface temperature sinusoidal fluctuations. Temperature distribution across the sample and heat flux density on one face are collected at the same six airflow conditions considered in the previous phases and compared to numerical results. The use of a cast concrete-based material provides enough flexibility in displacing thermal sensors across the section, allowing a sufficiently refined sampling of temperatures. This phase is used to evaluate the sources of errors unrelated to the numerical scheme parameters and to assess their effects on the model accuracy.

All the main aspects of each phase of this work are reported in Table 1: the origin of the reference data, the features of the boundary conditions, the materials considered and the main purposes of each phase.

\subsection{The physical model}

The whole section of a Breathing Wall is crossed by a conductive flux, caused by the indoor-outdoor temperature difference, and an advective one, generated by the imposed airflow. If we introduce the hypothesis of homogeneous and isotropic medium and one-dimensional heat flux, the heat transfer phenomenon can be described through a modified Fourier equation such as:

$$
(\rho c)_{w} \frac{\partial T}{\partial t}+u_{f}\left(\rho c_{p}\right)_{f} \frac{\partial T}{\partial x}=\lambda_{w} \frac{\partial^{2} T}{\partial x^{2}}
$$

where $T$ is the temperature distribution in the domain, assumed as a function of time $t$ and space $x, u_{f}$ is the airflow velocity across the wall and $\rho, c$ and $\lambda$ are the density, the specific heat (at constant pressure if $p$ subscript is indicated) and the thermal conductivity of porous material (subscript $w$ ) or air (subscript $f$ ). Eq. (1) is also based on the assumption of constant thermal-physical properties of the material (i.e. independent from temperature), that leads to the linearity of the differential problem, and local thermal equilibrium (Kaviany, 1995; Alongi and Mazzarella, 2015), that allows to neglect the interaction between the solid and fluid phase at microscopic level inside the porous material. It also implies that the thermal-physical properties of the porous material are calculated as the average between the fluid and the solid phase properties, weighted over the porosity (i.e. volume weighted average). Going more in detail about the domain, this work is focused on a single layer component, with the spatial coordinate from the outer surface $(x=0)$ to the inner one $(x=L)$.

Moreover, first type boundary conditions are considered and surface temperature values are imposed. The corresponding equations are:

$$
\begin{aligned}
& \text { outer surface } T(0, t)=T_{0}(t) \\
& \text { inner surface } T(L, t)=T_{L}(t)
\end{aligned}
$$

The work presented in this paper is based on steady periodic conditions, such as:

$$
T_{0}(t)=\bar{T}_{0}+\widetilde{T}_{0}(t)=\bar{T}_{0}+\sum_{k=1}^{n} \widetilde{T}_{0, k}(t)=\bar{T}_{0}+\sum_{k=1}^{n}\left[\Delta T_{0, a, k} \cdot \cos \left(\omega_{k} t+\psi_{0, a, k}\right)+\Delta T_{0, b, k} \cdot \sin \left(\omega_{k} t+\psi_{0, b, k}\right)\right]
$$




$$
T_{L}(t)=\bar{T}_{L}+\tilde{T}_{L}(t)=\bar{T}_{L}+\sum_{k=1}^{n} \tilde{T}_{L, k}(t)=\bar{T}_{L}+\sum_{k=1}^{n}\left[\Delta T_{L, a, k} \cdot \cos \left(\omega_{k} t+\psi_{L, a, k}\right)+\Delta T_{L, b, k} \cdot \sin \left(\omega_{k} t+\psi_{L, b, k}\right)\right]
$$

namely, the superposition of a steady state component $\left(\bar{T}_{0}\right.$ and $\left.\bar{T}_{L}\right)$ and a steady periodic component $\left(\widetilde{T}_{0}(t)\right.$ and $\left.\widetilde{T}_{L}(t)\right)$. The latter is generally made of $n$ sine and cosine waves, with a fluctuation $\left(\Delta T_{0, a, k}\right.$ and $\left.\Delta T_{L, a, k}\right)$, an angular frequency $\left(\omega_{k}\right)$ and a phase $\left(\psi_{0, a, k}\right.$ and $\left.\psi_{L, a, k}\right)$. Finally, as far as the angular frequency is concerned, it is defined as:

$$
\omega_{k}=k \cdot \omega_{1} \text { with } k=1 \div n
$$

where $\omega_{1}$ is the angular frequency of the main harmonic, calculated as:

$$
\omega_{1}=\frac{2 \pi}{T_{\text {day }}} \text { with } T_{\text {day }}=24 h=86400 \mathrm{~s}
$$

\subsection{The numerical model}

In order to be able to assess the thermal behaviour of Breathing Wall components and calculate the temperature distribution across their section for a given set of time-dependent Dirichlet boundary conditions, a one-dimension numerical algorithm is developed in Matlab ${ }^{\circledR}$, and the differential problem represented by Eqs. (1), (2) and (3) is studied using a Finite Difference Method. The central difference scheme is used to approximate both spatial derivatives (second order for the diffusive term and first order for the advective one), while the time variation is managed using the fully implicit representation (backward Euler), similarly to what is presented in (Wang et al., 2018).

Dividing Eq. (1) by the wall thermal capacity $(\rho c)_{w}$, all the thermal-physical properties can be summarized into:

$$
\begin{gathered}
\alpha_{w}=\frac{\lambda_{w}}{(\rho c)_{w}} \\
\gamma=u_{f} \frac{\left(\rho c_{p}\right)_{f}}{(\rho c)_{w}}
\end{gathered}
$$

namely, the porous medium thermal diffusivity $(\alpha)$ and the fluid scaled velocity $(\gamma)$. Moreover, the spatial domain is discretized into a structured grid with a constant $\Delta x$ step, while the temporal dimension is divided into intervals of time step $\Delta t$. If the space domain is divided into $N+1$ nodes and the time domain into $M+1$ nodes, the discrete field equation referred to the $i$-th node at the $j$-th time step becomes:

$$
\frac{T_{i}^{j+1}-T_{i}^{j}}{\Delta t}+\gamma \frac{T_{i+1}^{j+1}-T_{i-1}^{j+1}}{2 \Delta x}=\alpha \frac{T_{i+1}^{j+1}-2 T_{i}^{j+1}+T_{i-1}^{j+1}}{\Delta x^{2}} \text { with }\left\{\begin{array}{l}
i=1 \div N \\
j=0 \div M
\end{array}\right.
$$

Eq. (10) leads then to the following numerical scheme:

$$
T_{i+1}^{j+1}\left(\frac{\gamma \Delta t}{2 \Delta x}-\frac{\alpha \Delta t}{\Delta x^{2}}\right)+T_{i}^{j+1}\left(1+2 \frac{\alpha \Delta t}{\Delta x^{2}}\right)+T_{i-1}^{j+1}\left(-\frac{\gamma \Delta t}{2 \Delta x}-\frac{\alpha \Delta t}{\Delta x^{2}}\right)=T_{i}^{j}
$$

First type steady periodic boundary conditions defined according to Eqs. (4) and (5) become:

$$
T_{0}^{j}=\bar{T}_{0}+\sum_{k=1}^{n}\left[\Delta T_{0, a, k} \cdot \cos \left(\omega_{k} j \Delta t+\psi_{0, a, k}\right)+\Delta T_{0, b, k} \cdot \sin \left(\omega_{k} j \Delta t+\psi_{0, b, k}\right)\right] \text { at } x=0
$$




$$
T_{N}^{j}=\bar{T}_{N}+\sum_{k=1}^{n}\left[\Delta T_{N, a, k} \cdot \cos \left(\omega_{k} j \Delta t+\psi_{L, a, k}\right)+\Delta T_{N, b, k} \cdot \sin \left(\omega_{k} j \Delta t+\psi_{L, b, k}\right)\right] \text { at } x=N \Delta x=L
$$

while the initial condition is a linear distribution of temperature across the domain, based on the initial values of the boundary conditions:

$$
T_{i}^{0}=\frac{T_{N}^{0}-T_{0}^{0}}{L} i \Delta x+T_{0}^{0} \quad \text { at } t=0
$$

Finally, the temperature distribution at each time step is used to calculate the corresponding heat flux density at the $x=L$ surface. Both two-points and three-points formulations are used, respectively defined as:

$$
\begin{gathered}
\varphi_{L, 2 p t}^{j}=-\lambda_{w} \frac{T_{N}^{j}-T_{N-1}^{j}}{\Delta x} \\
\varphi_{L, 3 p t}^{j}=-\lambda_{w} \frac{3 T_{N}^{j}-4 T_{N-1}^{j}+T_{N-2}^{j}}{2 \Delta x}
\end{gathered}
$$

According to literature related to numerical methods for the advection-diffusion equation, such as (Zheng and Bennett, 2002), with the central difference scheme the approximation of the advection term is accurate to the second order as is the diffusion term. Compared to the upstream scheme approximation of the advection term, the central difference approximation does not lead to numerical dispersion but may provide artificial numerical oscillations. However, the oscillatory behavior is eliminated if $P e ́<2$, where

$$
P \text { é }=\frac{\left(\rho c_{p}\right)_{f} u_{f} \Delta x}{\lambda_{w}}
$$

is the grid Pécler number. As far as the implicit time scheme is concerned, it is unconditionally stable.

Finally, the specifics of the computer used to run the algorithm are:

- operative system - Windows 10 Pro (64bit, version 1909)

- $\quad$ software version - Matlab ${ }^{\circledR}$ R2017b

- processor - Intel ${ }^{\circledR}$ Core i7-4790K $(4.00 \mathrm{GHz})$

- motherboard chipset - Z97

- $\quad$ ram - 32 GB (DDR3)

- $\quad$ drive - Intel ${ }^{\circledast}$ SSD

\subsection{The analytical model}

The validation process is based on the comparison with the analytical model described and validated in (Alongi et al., 2020). Going more in detail, for the given set of boundary conditions based on Eqs. (4) and (5), the solution of the linear heat transfer problem can be defined as:

$$
T(x, t)=\bar{T}(x)+\tilde{T}(x, t)=\bar{T}(x)+\sum_{k=1}^{n}\left[\Delta T_{a, k}(x) \cdot \cos \left(\omega_{k} t+\psi_{a, k}\right)+\Delta T_{b, k}(x) \cdot \sin \left(\omega_{k} t+\psi_{b, k}\right)\right]
$$

The steady state component $\bar{T}(x)$ is calculated using the equation proposed by (Taylor et al., 1996) and validated in (Alongi et al., 2017b) as:

$$
\bar{T}(x)=\frac{e^{\frac{P e}{L} x}-1}{e^{P e}-1}\left(\bar{T}_{L}-\bar{T}_{0}\right)+\bar{T}_{0}
$$

where Péclet number $(\mathrm{Pe})$ referring to the wall thickness is defined as: 


$$
P e=u_{f} \frac{\left(\rho c_{p}\right)_{f}}{\lambda_{w}} L
$$

At the same time, the sine and cosine components of the steady periodic part $\tilde{T}(x, t)$ are given by:

$$
\begin{aligned}
\Delta T_{a, k}(x) \cdot \cos \left(\omega_{k} t+\psi_{a, k}\right) & =\Re\left[\tilde{\vartheta}_{a, k}(x, t)\right] \\
\Delta T_{b, k}(x) \cdot \sin \left(\omega_{k} t+\psi_{b, k}\right) & =\Im\left[\tilde{\vartheta}_{b, k}(x, t)\right]
\end{aligned}
$$

where $\tilde{\vartheta}_{j, k}(x, t)$ is the complex temperature fluctuation defined as:

$$
\tilde{\vartheta}_{j, k}(x, t)=\left[\Delta T_{j}(x) e^{i \psi_{j, k}(x)}\right] e^{i \omega_{k} t}=\tilde{\vartheta}_{j, k}(x) e^{i \omega_{k} t} \text { with } j=a, b
$$

Finally, the space-dependent temperature complex fluctuation is calculated as:

$$
\tilde{\vartheta}_{j, k}(x)=e^{\frac{P e \cdot x}{2 L}} \frac{\sinh \left[\tilde{\beta}_{k}(L-x)\right]}{\sinh \left(\tilde{\beta}_{k} L\right)} \tilde{\vartheta}_{0, j, k}+e^{\frac{P e}{2}\left(\frac{x}{L}-1\right)} \frac{\sinh \left(\tilde{\beta}_{k} x\right)}{\sinh \left(\tilde{\beta}_{k} L\right)} \tilde{\vartheta}_{L, j, k} \text { with } j=a, b
$$

where

$$
\begin{gathered}
\tilde{\vartheta}_{0, j, k}=\Delta T_{0, j, k}(x) e^{i \psi_{0, j, k}} \text { with } j=a, b \\
\tilde{\vartheta}_{L, j, k}=\Delta T_{L, j, k}(x) e^{i \psi_{L, j, k}} \text { with } j=a, b \\
\tilde{\beta}_{k}=\sqrt{\frac{P e^{2}}{2 L^{2}}+i \frac{\omega_{k}}{\alpha_{w}}}
\end{gathered}
$$

The analytical model also allows the calculation of the conductive heat flux density fluctuation at any given point in the domain, again using the superposition of the steady state (Eq. (28)) and the fluctuating (Eq. (29)) components defined as:

$$
\bar{\varphi}_{c d}(x)=-\lambda_{w} \frac{d \bar{T}(x)}{d x}=-\frac{P e}{R_{c d}} \frac{e^{\frac{P e}{L} x}}{e^{P e}-1}\left(\bar{T}_{L}-\bar{T}_{0}\right)
$$

where $R_{c d}$ is the wall thermal resistance, namely the reciprocal of the wall conductance $C_{0}$,

$$
\begin{aligned}
\tilde{\varphi}_{c d, k}(x)=-\lambda_{w} & \frac{d \tilde{\vartheta}_{j, k}(x)}{d x}= \\
= & -\lambda_{w} e^{\frac{P e \cdot x}{2 L}}\left\{\frac{P e}{2 L} \frac{\sinh \left[\tilde{\beta}_{k}(L-x)\right]}{\sinh \left(\tilde{\beta}_{k} L\right)}-\tilde{\beta}_{k} \frac{\cosh \left[\tilde{\beta}_{k}(L-x)\right]}{\sinh \left(\tilde{\beta}_{k} L\right)}\right\} \tilde{\vartheta}_{0, j, k} \\
& -\lambda_{w} e^{\frac{P e}{2}\left(\frac{x}{L}-1\right)}\left[\frac{P e}{2 L} \frac{\sinh \left(\tilde{\beta}_{k} x\right)}{\sinh \left(\tilde{\beta}_{k} L\right)}-\tilde{\beta}_{k} \frac{\cosh \left(\tilde{\beta}_{k} x\right)}{\sinh \left(\tilde{\beta}_{k} L\right)}\right] \tilde{\vartheta}_{L, j, k} \text { with } j=a, b
\end{aligned}
$$

The steady state component of the heat flux density in Eq. (28) can also be used to define an effective thermal conductance of the Breathing Wall ( $C_{B W}, C_{O}$ when the quantity is referred to a traditional wall), using the definition presented in (Imbabi, 2006; Imbabi, 2012):

$$
C_{B W}=-\frac{\bar{\varphi}_{c d}(0)}{\bar{T}_{L}-\bar{T}_{0}}=\frac{P e}{R_{c d}} \frac{1}{e^{P e}-1}
$$

For the sake of this work, the heat flux density obtained through numerical calculations is compared to the analytical one at the inner edge of the domain $(x=L)$. More details about the derivation of the analytical model and the mathematical procedure to divide $\tilde{\beta}_{k}, \tilde{\vartheta}_{j, k}(x)$ and $\tilde{\varphi}_{c d, k}$ into their real and imaginary parts, can be found in (Alongi et al., 2020). 


\subsection{The experimental setup}

The performance of the numerical model is evaluated experimentally through direct comparison with temperature distribution measurements collected using a laboratory rig called Dual Air Vented Thermal Box (DAVTB). This setup is able to test small scale samples of building envelope technologies under user-defined thermal boundary conditions (either steady state or steady periodic) and force a controlled airflow through permeable components (e.g. Breathing Walls). A detailed description is provided in previous works by the Authors (Alongi and Mazzarella, 2015; Alongi et al., 2017a, Alongi et al., 2020).

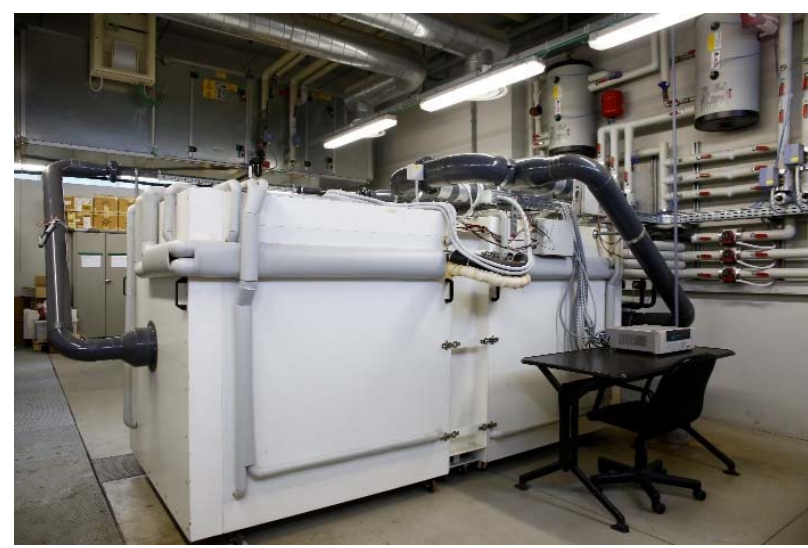

Figure 1: the DAVTB facility.

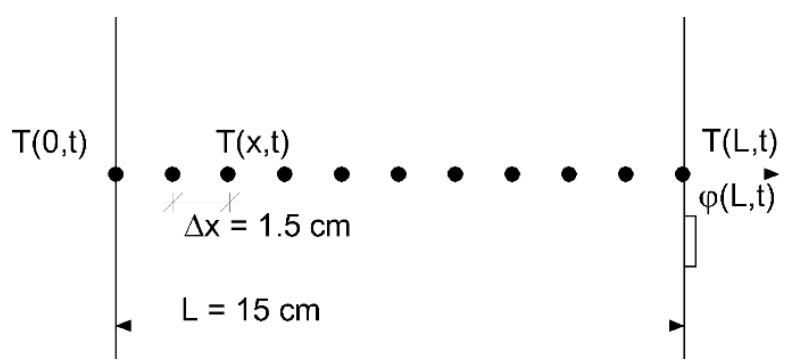

Figure 2: temperature and heat flow measurements inside and at the surfaces of the sample wall.

The facility (Figure 1) consists of two insulated chambers named Box 1 and Box 2 (each $1.5 \mathrm{~m}$ wide $\times 1.5 \mathrm{~m}$ high $\times 1.29 \mathrm{~m}$ long) separated by the $1.5 \mathrm{~m} \times 1.5 \mathrm{~m}$ insulated metal frame that accommodates the sample. The chambers are externally connected by the air recirculation system, used to generate an airflow through the sample itself. The set-point operative temperature is defined separately in each chamber in a range between $15^{\circ} \mathrm{C}$ and $50^{\circ} \mathrm{C}$ and is achieved by means of a dedicated hydronic system providing both heating and cooling power through radiant panels inside the two boxes.

The measurement and control system in the DAVTB apparatus is based on an Agilent 34980A multifunctional switch unit, remotely controlled through a dedicated LabVIEW algorithm. Temperature measurements are performed in several points of the hydraulic plant, in various locations inside each chamber and inside the sample wall, using T-type calibrated thermocouples (TC). Moreover, a globe thermometer is installed in the geometrical center of each chamber to measure the operative temperature. As a result of the calibration process, for all temperature probes an accuracy of $0.15^{\circ} \mathrm{C}$ can be considered. Finally, a $4.4 \mathrm{~mm} \times 4.4 \mathrm{~mm}$ heat flux meter (gSKIN ${ }^{\circledR}-$ XM $269 \mathrm{C}$ ) is installed on the sample surface facing Box 2 , featuring a $\pm 3 \%$ calibration accuracy according to the manufacturer GreenTeg. The average air velocity across the sample is measured through a bi-directional fan anemometer located in a dedicated section of the air recirculation pipe. The anemometer, a vane wheel sensor produced by Hoentzsch $\mathrm{GmbH}$, operates in the range $\pm(0.4 \div 20) \mathrm{m} / \mathrm{s}$, and the accuracy of the overall measurement chain is assessed at $\pm 1.3 \cdot 10^{-4} \mathrm{~m} / \mathrm{s}$.

As far as the sample is concerned, in this work the analysis is focused on a $0.15 \mathrm{~m}$ thick single layer Breathing Wall component based on no-fines concrete. The wall is also divided into nine $0.32 \mathrm{~m} \times 0.32 \mathrm{~m}$ blocks and thermocouples are embedded in the centermost section, with nine probes displaced at $1.5 \mathrm{~cm}$ apart from each other and two more to measure the surface temperatures (Figure 2).

\section{Results and discussion}

The outcomes of the three phases of the validation and performance assessment process (Table 1) are presented in this section. As previously stated, the validation is performed by comparing numerical results to corresponding analytical ones, involving a capacitive and a resistive material alternatively.

The capacitive material considered, also involved in the third part of this work, is no-fines, that consists of a cement-based mixture involving large aggregates only (i.e. gravel with an average diameter in the range $6 \mathrm{~mm} \div 12 \mathrm{~mm}$ ) and features a highly interconnected porous matrix (Wong, 2007; Alongi et al., 2017a). Its 
thermal-physical properties have been experimentally assessed through Transient Plane Source technique, mass and volume measurements performed on dedicated samples (Alongi et al., 2017a; Alongi et al., 2017b). As far as the resistive material is concerned, mineral wool is considered in this work. In this case, thermalphysical properties are taken from data sheet related to a commercial product. In both cases, the domain dimension (namely, the wall thickness) is assumed to be equal to $0.15 \mathrm{~m}$, which is also the thickness of the wall sample experimentally investigated in the third phase of this work. All the values of the thermal-physical properties are listed in Table 2, along with the air properties used in this work.

Table 2: thermal-physical properties of air and no-fines concrete used in this work.

\begin{tabular}{cccc}
\hline quantity & air & no-fines concrete & mineral wool \\
\hline porosity $\varepsilon$ & - & $(30 \pm 2) \%$ & - \\
density $\rho$ & $1.23 \mathrm{~kg} / \mathrm{m}^{3}$ & $(1738 \pm 61) \mathrm{kg} / \mathrm{m}^{3}$ & $50 \mathrm{~kg} / \mathrm{m}^{3}$ \\
specific heat capacity $c$ & $1004.9 \mathrm{~J} /(\mathrm{kg} \cdot \mathrm{K})$ & $(1011 \pm 110) \mathrm{J} /(\mathrm{kg} \cdot \mathrm{K})$ & $1000 \mathrm{~J} /(\mathrm{kg} \cdot \mathrm{K})$ \\
thermal conductivity $\lambda$ & $0.025 \mathrm{~W} /(\mathrm{m} \cdot \mathrm{K})$ & $(1.24 \pm 0.09) \mathrm{W} /(\mathrm{m} \cdot \mathrm{K})$ & $0.035 \mathrm{~W} /(\mathrm{m} \cdot \mathrm{K})$ \\
\hline
\end{tabular}

These two materials are considered in this work to study the effects of different properties on the heat transfer phenomenon and its numerical description, along with any possible influence on the definition of optimized discretization parameters. In order to highlight the diversity of a BW composed of either no-fines concrete or mineral wool, Eq. (30) is used to calculate the ratio between the effective thermal conductance and the airtight wall conductance $C_{B W} / C_{O}$ (Imbabi, 2006; Imbabi 2012) as a function of the airflow velocity. As Figure 3 clearly shows, the effective thermal conductance of the mineral wool BW is much more sensitive to the air velocity compared to the no-fines concrete, so that if air flows in contra-flux at a few $\mathrm{mm} / \mathrm{s}$ the ratio $C_{B W} / C_{0}$ quickly drops to zero.

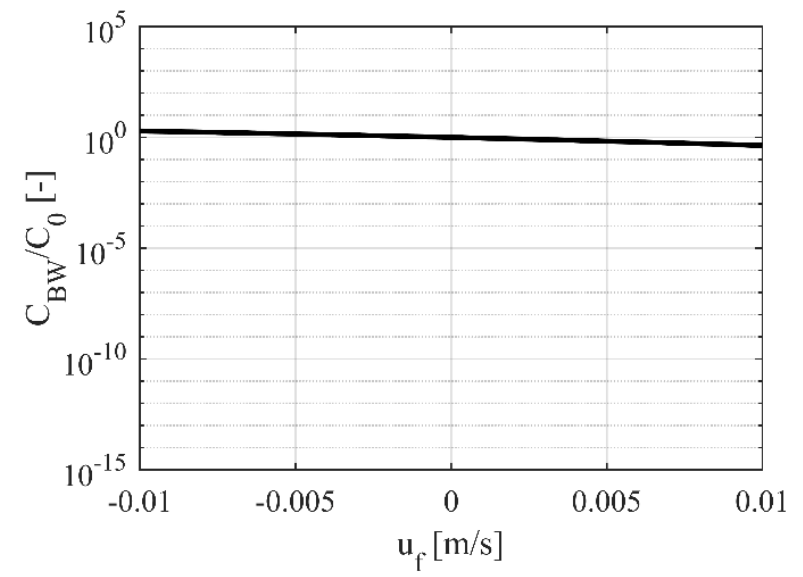

(a)

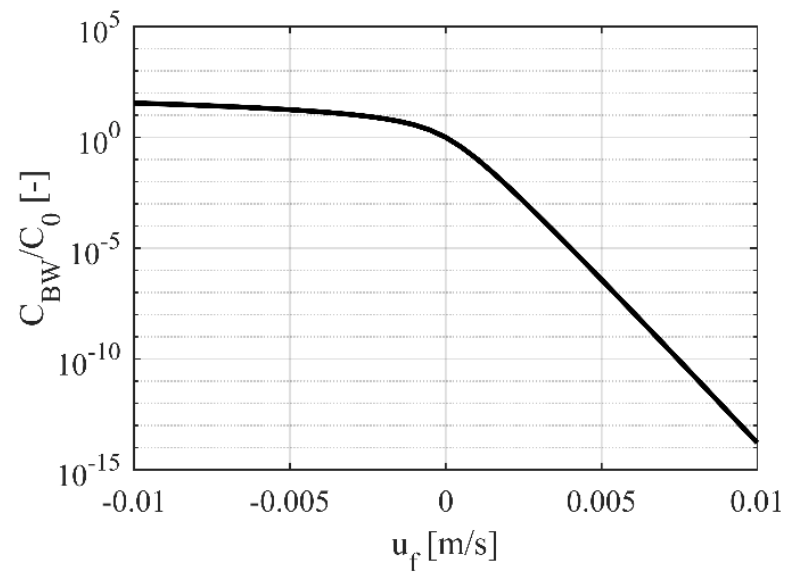

(b)

Figure 3: ratio $\mathrm{C}_{\mathrm{BW}} / \mathrm{C}_{0}$ as a function of the airflow velocity for a (a) no-fines concrete and a (b) mineral wool $0.15 \mathrm{~m}$ thick wall. Positive values of the velocity stand for contra-flux operation, the opposite for pro-flux.

At this stage of the work, material properties are considered constant and no moisture transport is considered, since neither the analytical references nor the experimental setup can handle water vapor distribution across the material. However, the future development will include this feature, along with a probabilistic approach similar to the one proposed in (Gradeci et al., 2018), and will provide a useful tool for performance evaluation of real BW components in the design process.

\subsection{Analytical validation}

This part of the work is aimed at validating the numerical model against the analytical solution of the heat transfer problem in BW components subjected to steady periodic conditions. The first phase deals with simple sinusoidal conditions and investigates the effects of discretization parameters, airflow velocity and material properties on the overall accuracy of the model. A similar analysis is then performed in the second phase, which features a more complex fluctuation of the outdoor boundary condition, and is aimed at studying the process to find optimized discretization parameters and assessing the numerical model ability to manage boundary conditions that are more similar to measured climatic ones. 


\subsubsection{Sinusoidal boundary conditions}

In the Phase 1 of this work, the simulation domain, either composed by no fines concrete or mineral wool, is exposed to a sinusoidal temperature variation on the outdoor surface $(x=0)$ and a constant temperature on the indoor surface $(\mathrm{x}=\mathrm{L})$. In order to achieve a stabilized steady periodic condition, every simulation is 10 days long and the last 24 hours are considered for the investigations. All values used in Eqs. (4) and (5) to define Dirichlet boundary conditions are reported in Table 3.

Table 3: values used to calculate the sinusoidal boundary conditions.

\begin{tabular}{cc}
\hline outdoor & indoor \\
\hline $\bar{T}_{0}=26^{\circ} \mathrm{C}$ & $\bar{T}_{L}=26^{\circ} \mathrm{C}$ \\
$\Delta T_{0, a, k}=0^{\circ} \mathrm{C} \forall k=1 \div n$ & $\Delta T_{L, a, k}=0^{\circ} \mathrm{C} \forall k=1 \div n$ \\
$\Delta T_{0, b, 1}=6^{\circ} \mathrm{C}$ & $\Delta T_{L, b, k}=0^{\circ} \mathrm{C} \forall k=1 \div n$ \\
$\Delta T_{0, b, k}=0^{\circ} \mathrm{C} \forall k=2 \div n$ & \\
\hline
\end{tabular}

As far as the airflow velocity is concerned, six levels are defined. A reference airtight condition is simulated $\left(u_{\mathrm{f}}=0 \mathrm{~m} / \mathrm{s}\right)$, along with five more values that cover a working range typical for the BW technology $(0.001 \mathrm{~m} / \mathrm{s}$, $0.003 \mathrm{~m} / \mathrm{s}, 0.006 \mathrm{~m} / \mathrm{s}, 0.009 \mathrm{~m} / \mathrm{s}$ and $0.012 \mathrm{~m} / \mathrm{s}$ ).

Dealing now with the discretization parameters, a sensitivity analysis is performed to investigate their effect on the numerical results. The whole group of airflow conditions is first simulated assuming a reference condition where $\Delta t=3600 \mathrm{~s}$ and $\Delta \mathrm{x}=0.001 \mathrm{~m}$. Then, both quantities are progressively refined to search for optimized values and evaluate the corresponding computational cost: every setting is used to run 10 identical simulations and the corresponding simulation time is recorded and averaged, in order to neglect the possible slowing effects of background processes running on the computer. Going more in detail, the values assumed in this phase for space grid and timestep are reported in Table 4.

Table 4: space and time discretization parameters used for the sensitivity analysis.

Grid Pé number are calculated at $0.012 \mathrm{~m} / \mathrm{s}$

\begin{tabular}{cccc}
\hline $\begin{array}{c}\text { spatial discretization } \\
\Delta \boldsymbol{x}\end{array}$ & $\begin{array}{c}\text { timestep } \\
\Delta t\end{array}$ & $\begin{array}{c}\text { Pémax } \\
\text { no fines concrete }\end{array}$ & $\begin{array}{c}\text { Pémax } \\
\text { rock wool }\end{array}$ \\
\hline $0.001 \mathrm{~m}$ & $3600 \mathrm{~s}$ & 0.012 & 0.478 \\
$0.0005 \mathrm{~m}$ & $1800 \mathrm{~s}$ & 0.006 & 0.239 \\
$0.00025 \mathrm{~m}$ & $900 \mathrm{~s}$ & 0.003 & 0.120 \\
\hline
\end{tabular}

These values are combined in order to obtain a set of 9 simulations for every airflow condition involved. In Table 4 the grid Péclet number at the maximum air flow velocity considered i.e. $0.012 \mathrm{~m} / \mathrm{s}$ is also reported for the two materials adopted in the BW, showing that the condition Pé< 2 is always satisfied and thus artificial oscillations are not expected. The Péclet numbers also show that advection plays a major role in the rock wool based BW than in the no fines concrete one.

Temperature distributions and surface heat flux density fluctuations are reported below for both materials considered in this work, followed by the discussion of the corresponding simulation errors and computational costs. 


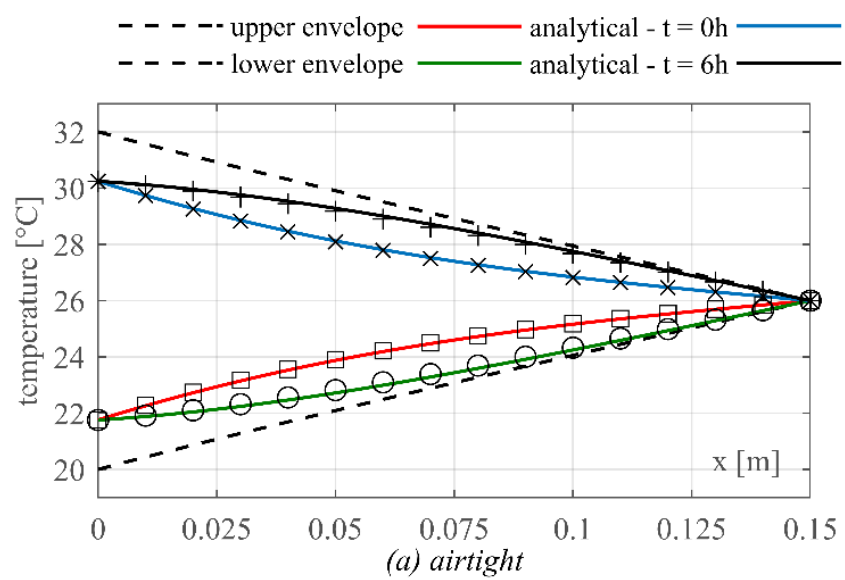

analytical $-\mathrm{t}=12 \mathrm{~h} \quad \square$ numerical $-\mathrm{t}=0 \mathrm{~h} \times$ numerical $-\mathrm{t}=12 \mathrm{~h}$
analytical $-\mathrm{t}=18 \mathrm{~h} \bigcirc$ numerical $-\mathrm{t}=6 \mathrm{~h}+$ numerical $-\mathrm{t}=18 \mathrm{~h}$
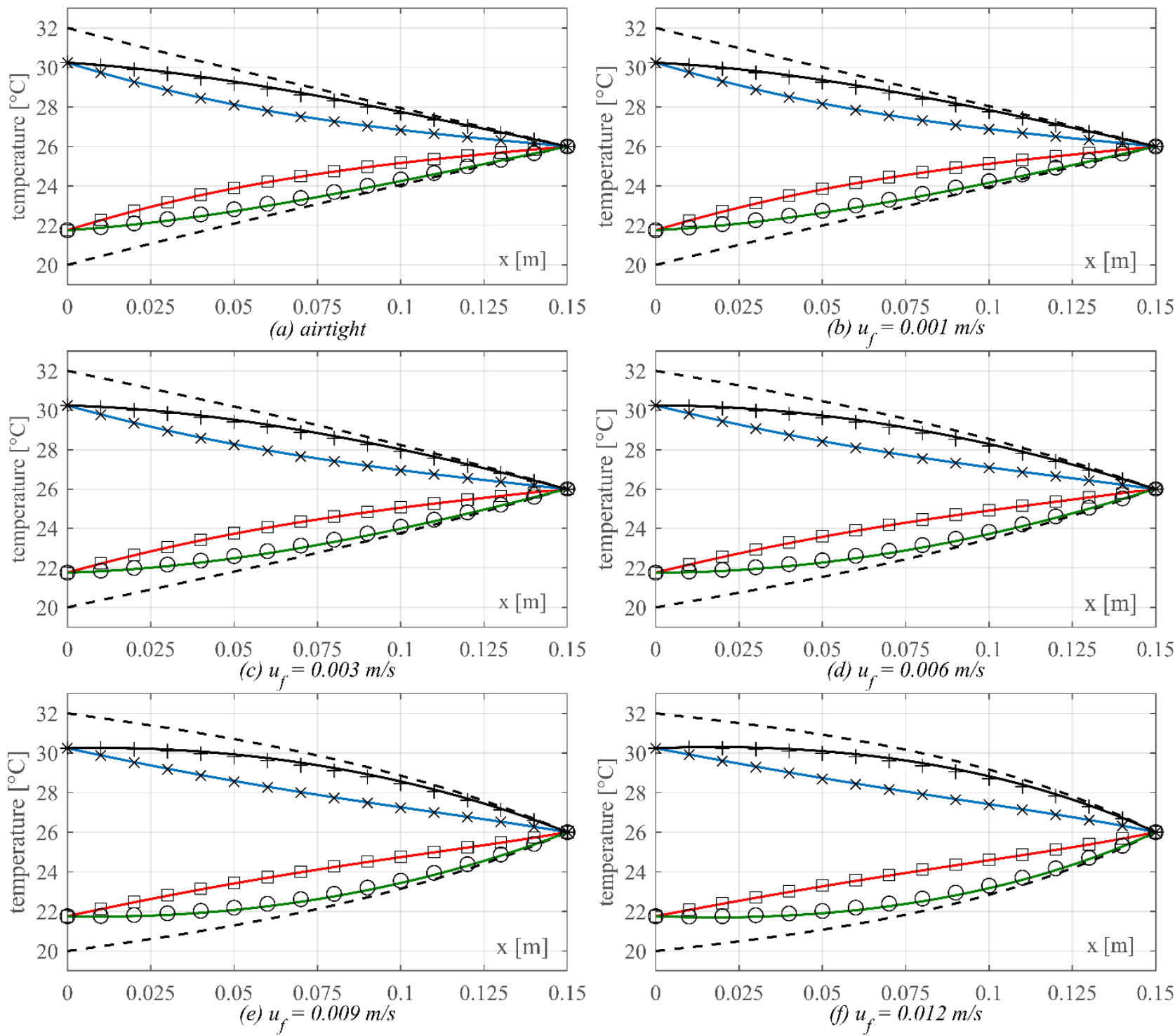

Figure 4:no fines concrete - comparison between analytical and numerical temperature distributions at four timestamps ( $t=0 \mathrm{~h}, t=6 \mathrm{~h}, t=12 \mathrm{~h}$ and $t=18 \mathrm{~h}$ ) for six airflow conditions: (a) airtight, (b) $0.001 \mathrm{~m} / \mathrm{s}$, (c) $0.003 \mathrm{~m} / \mathrm{s}$, (d) $0.006 \mathrm{~m} / \mathrm{s}$, (e) $0.009 \mathrm{~m} / \mathrm{s}$ and (f) $0.012 \mathrm{~m} / \mathrm{s}$. Numerical simulations performed with $\Delta x=0.001 \mathrm{~m}$ and $\Delta t=3600 \mathrm{~s}$.

For the given set of conditions, the no fines concrete displays a small influence of the advective term over the overall heat transfer phenomena, as shown in Figure 4: all airflow conditions feature a slight curvature that increases with growing velocities. Moreover, the thermal gradient appears to be distributed over the whole spatial domain.

As far as the numerical model performance is concerned, Figure 4 qualitatively shows how the numerical scheme with (coarse) standard discretization parameters effectively replicates the analytical reference. 


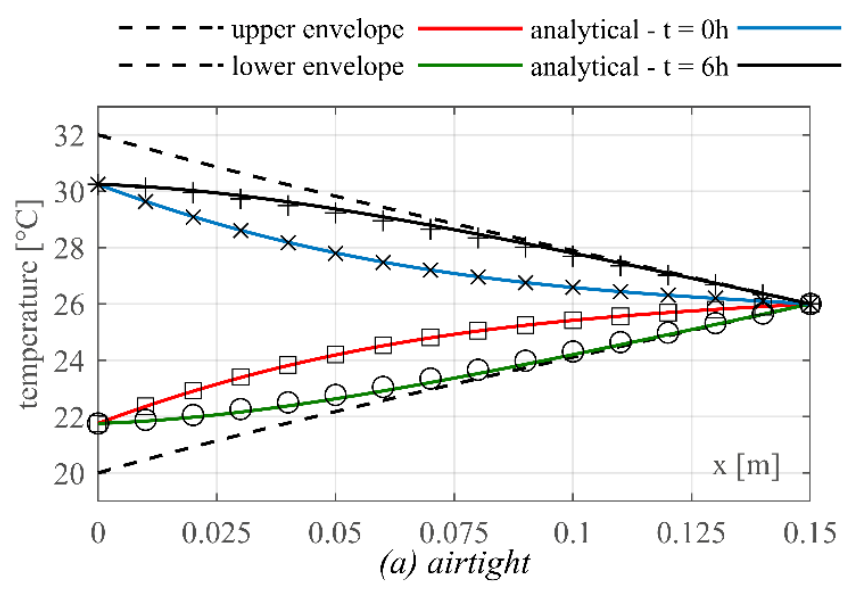

analytical $-\mathrm{t}=12 \mathrm{~h} \quad \square$ numerical $-\mathrm{t}=0 \mathrm{~h} \times$ numerical $-\mathrm{t}=12 \mathrm{~h}$

analytical $-\mathrm{t}=18 \mathrm{~h} \bigcirc$ numerical $-\mathrm{t}=6 \mathrm{~h}+$ numerical $-\mathrm{t}=18 \mathrm{~h}$
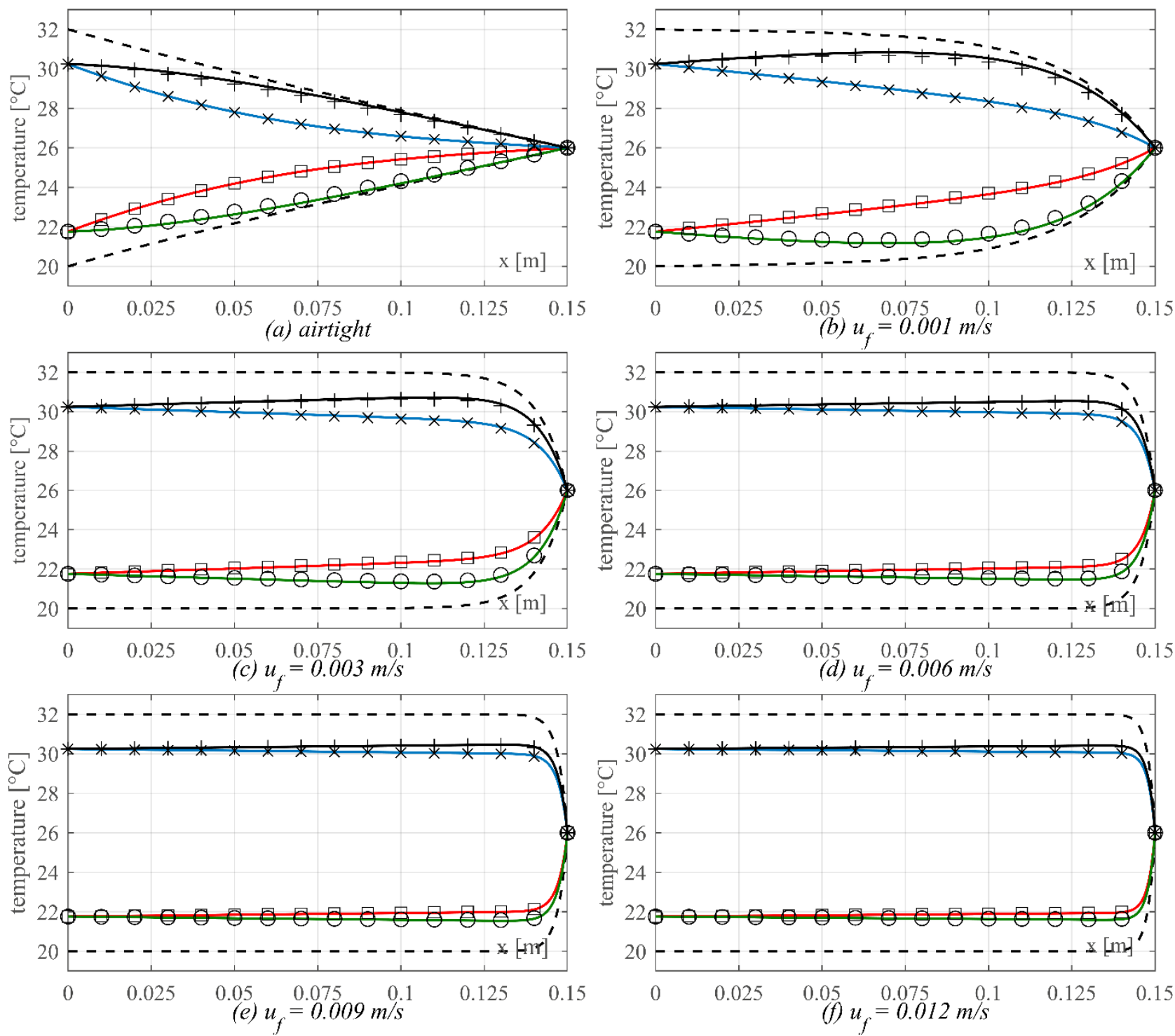

Figure 5: mineral wool - comparison between analytical and numerical temperature distributions at four timestamps $(t$ $=0 \mathrm{~h}, t=6 \mathrm{~h}, t=12 \mathrm{~h}$ and $t=18 \mathrm{~h}$ ) for six airflow conditions: (a) airtight, (b) $0.001 \mathrm{~m} / \mathrm{s}$, (c) $0.003 \mathrm{~m} / \mathrm{s},(d) 0.006 \mathrm{~m} / \mathrm{s}$, (e) $0.009 \mathrm{~m} / \mathrm{s}$ and (f) $0.012 \mathrm{~m} / \mathrm{s}$. Numerical simulations performed with $\Delta x=0.001 \mathrm{~m}$ and $\Delta t=3600 \mathrm{~s}$.

The outcomes of the same group of conditions applied to the mineral wool are reported in Figure 5 and compared to the corresponding analytical model results. It is possible to observe that the deviation from the airtight temperature distribution is more prominent than the one displayed in Figure 4. This comparison confirms that the resistive material is more sensitive to the advective component of the heat transfer phenomenon than what observed for the capacitive material, as already shown by the trend of the effective conductance in Figure 3 and by the grid Pé in Table 4. Moreover, Figure 5 demonstrates that, when an insulating material is used as BW component with airflow directed from outdoor to indoor, the thermal gradient is increasingly concentrated toward the inside face as the air velocity grows. Even though at $u_{f}=$ $0.001 \mathrm{~m} / \mathrm{s}$ the whole domain is involved by the temperature gradient (Figure 5(b)), when uf grows above $0.006 \mathrm{~m} / \mathrm{s}$ the most part of temperature variation across space at any given timestamp is concentrated within the last centimeters toward the indoor bound, while in the rest of the domain the temperature is almost constant and close to the outdoor boundary condition (Figure 5(d), (e), (f)).

Like what observed in Figure 4, the numerical model seems to adequately reproduce the analytical outcomes from a qualitative standpoint. Quantitative analyses are provided later in this section. 


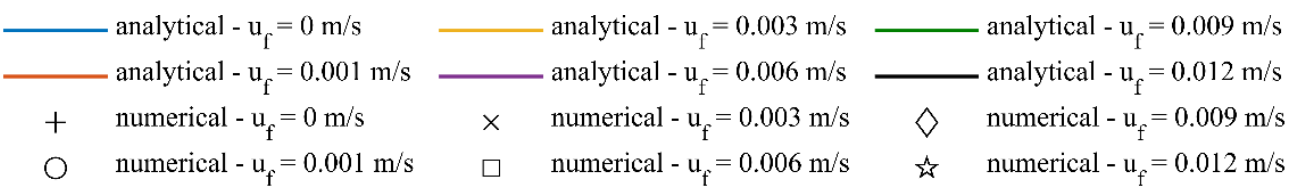

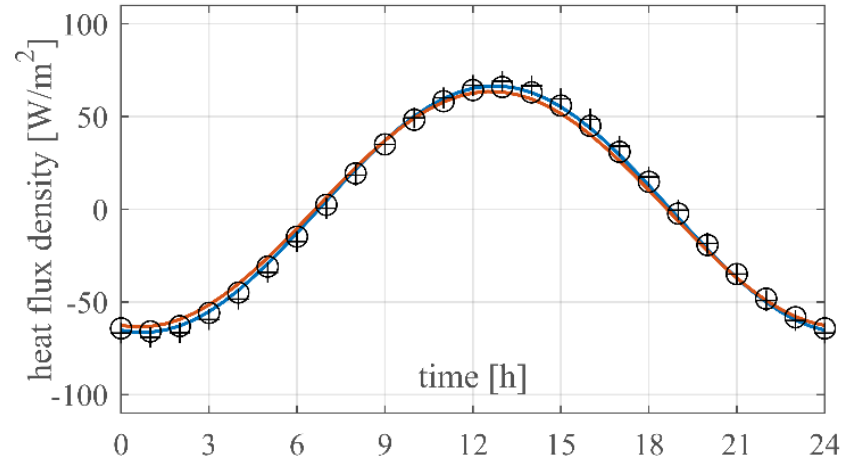

(a) $\varphi(0, \mathrm{t})-0 \mathrm{~m} / \mathrm{s}, 0.001 \mathrm{~m} / \mathrm{s}$

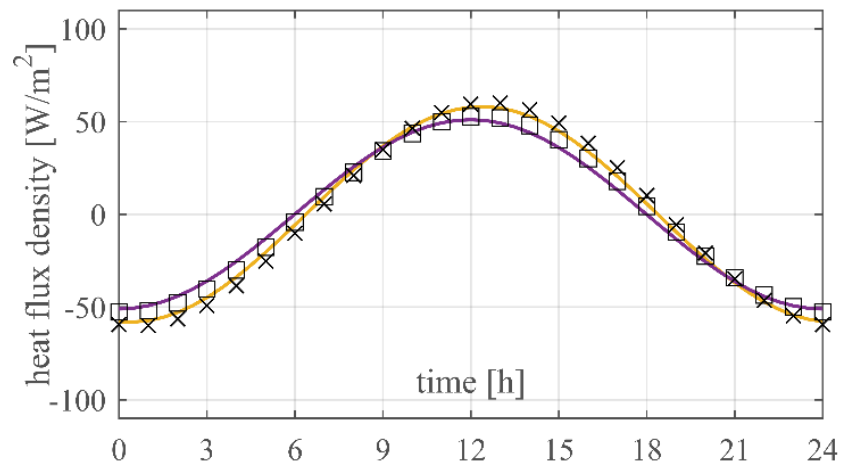

(c) $\varphi(0, \mathrm{t})-0.003 \mathrm{~m} / \mathrm{s}, 0.006 \mathrm{~m} / \mathrm{s}$

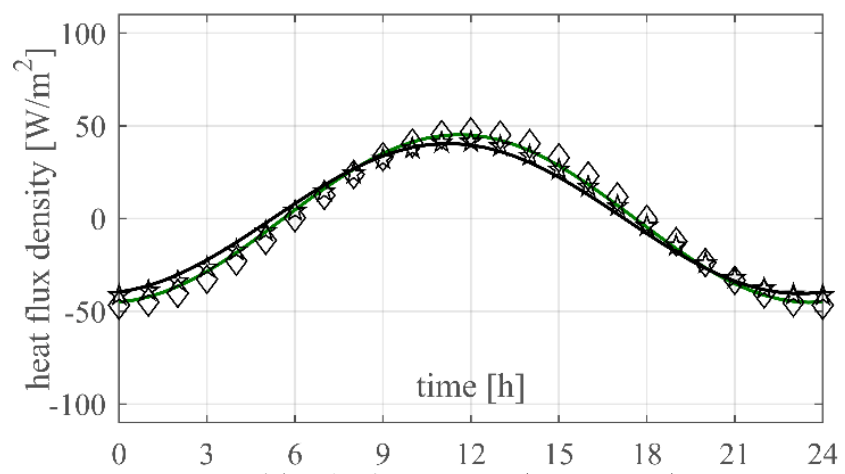

(e) $\varphi(0, \mathrm{t})-0.009 \mathrm{~m} / \mathrm{s}, 0.012 \mathrm{~m} / \mathrm{s}$

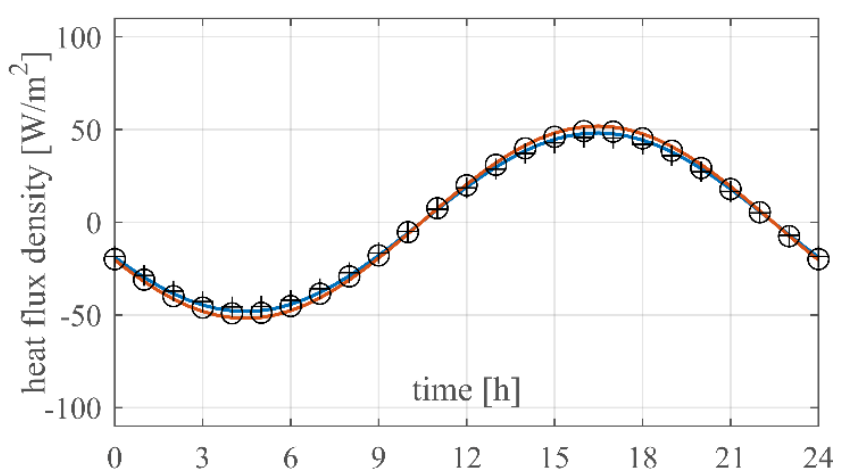

(b) $\varphi(\mathrm{L}, \mathrm{t})-0 \mathrm{~m} / \mathrm{s}, 0.001 \mathrm{~m} / \mathrm{s}$

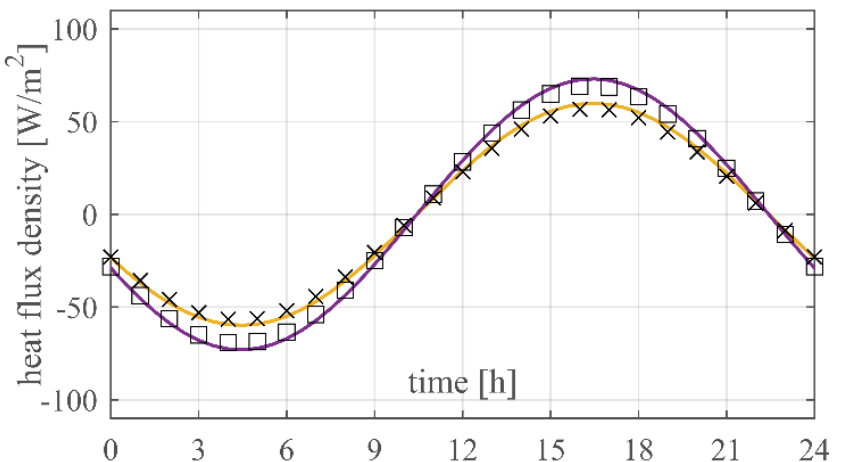

(d) $\varphi(\mathrm{L}, \mathrm{t})-0.003 \mathrm{~m} / \mathrm{s}, 0.006 \mathrm{~m} / \mathrm{s}$

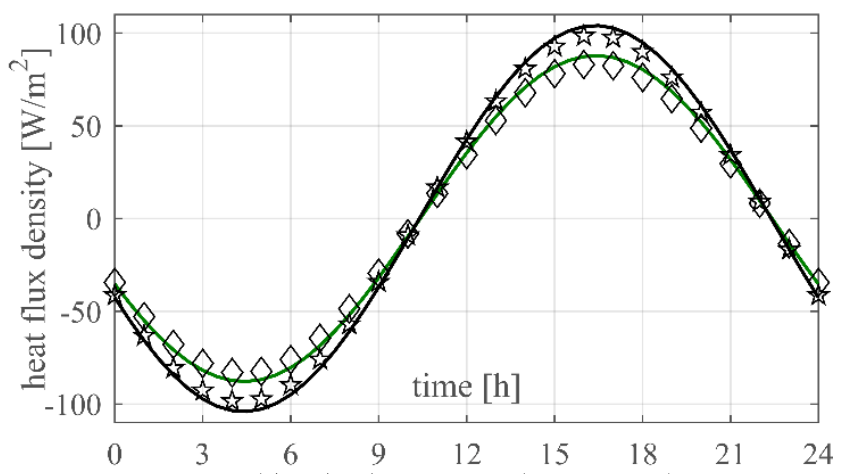

(f) $\varphi(\mathrm{L}, \mathrm{t})-0.009 \mathrm{~m} / \mathrm{s}, 0.012 \mathrm{~m} / \mathrm{s}$

Figure 6: no fines concrete - comparison between analytical and numerical heat flux density fluctuations for six airflow conditions: (a) airtight and $0.001 \mathrm{~m} / \mathrm{s}$ at $x=0$, (b) airtight and $0.001 \mathrm{~m} / \mathrm{s}$ at $x=L$, (c) 0.003 and $0.006 \mathrm{~m} / \mathrm{s}$ at $x=0$, (d) 0.003 and $0.006 \mathrm{~m} / \mathrm{s}$ at $x=L$, (e) 0.009 and $0.012 \mathrm{~m} / \mathrm{s}$ at $x=0$, (f) 0.009 and $0.012 \mathrm{~m} / \mathrm{s}$ at $x=$ L. Numerical simulations performed with $\Delta x=0.001 \mathrm{~m}$ and $\Delta t=3600 \mathrm{~s}$.

The heat flux density fluctuation at the edges of the domain (Figure 6) calculated for the no fines concrete, both numerically and analytically, is affected by the temperature distribution described in Figure 4 . The increase in airflow velocity progressively decreases the heat exchange at the outdoor surface while increasing that at the indoor one, as typically shown by a BW component crossed by an airflow directed from outdoor to indoor: namely, the temperature gradient decreases at $\mathrm{x}=0$ and increases at $\mathrm{x}=\mathrm{L}$.

As far as the comparison between numerical and analytical results is concerned, the numerical model seems to correctly represent the exact solution, with a progressive underestimation of the indoor surface heat flux density amplitude at the indoor surface as the airflow velocity grows. This deviation could be related to the local derivative approximation done using Eq. (15), that neglects the local curvature and linearly interpolates the temperature distribution between the points $\mathrm{N}-1$ and $\mathrm{N}$. 


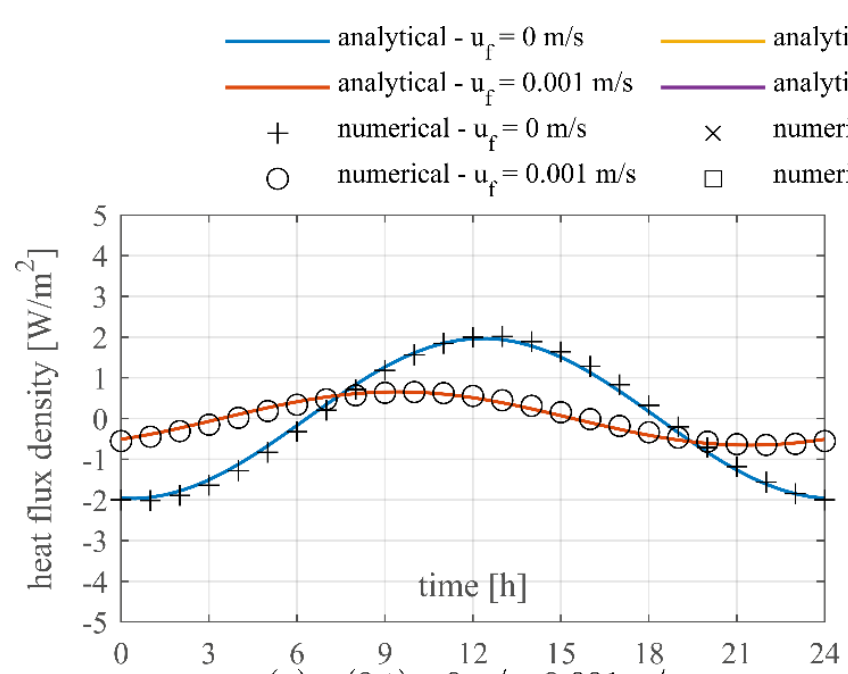

(a) $\varphi(0, \mathrm{t})-0 \mathrm{~m} / \mathrm{s}, 0.001 \mathrm{~m} / \mathrm{s}$
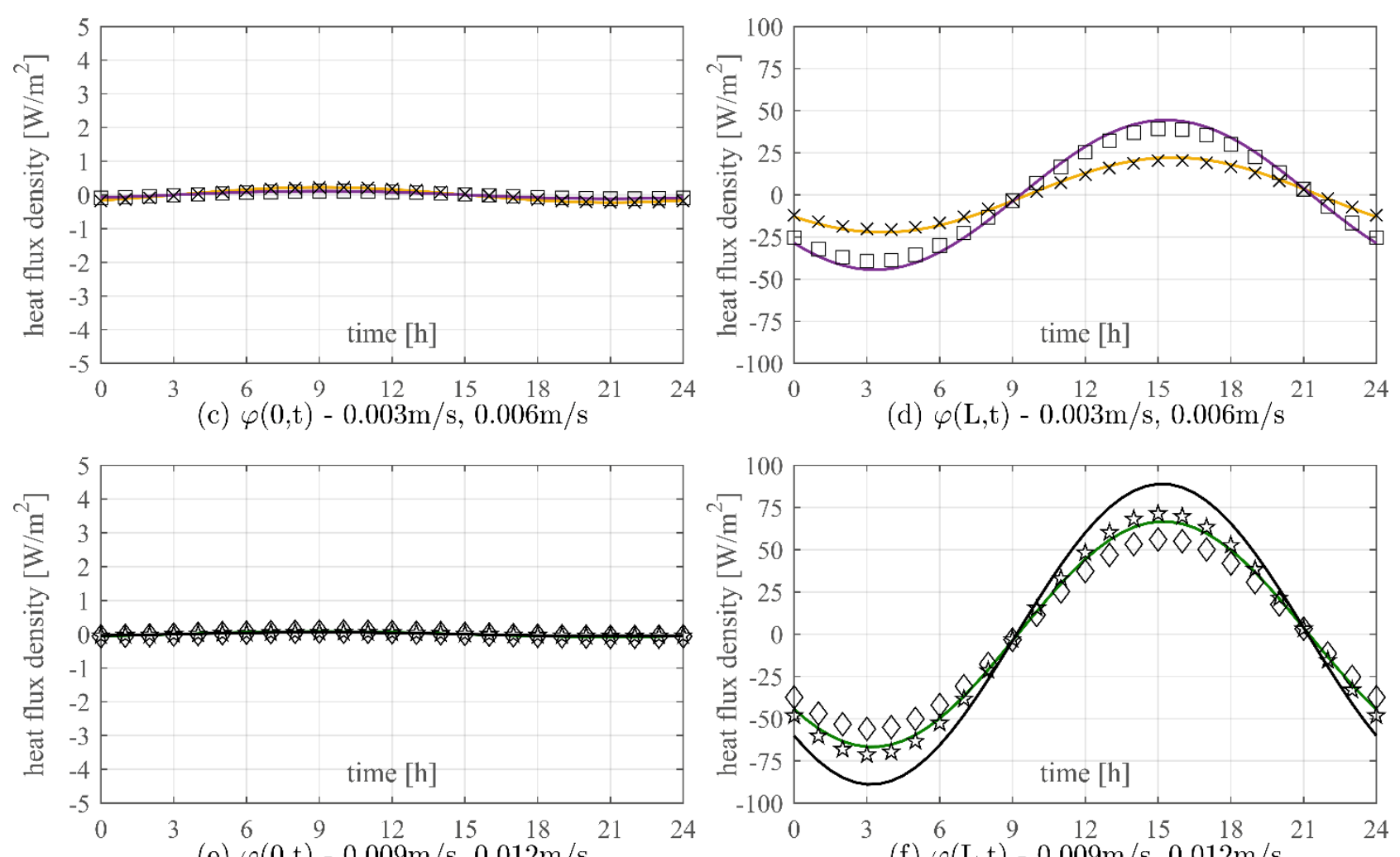

Figure 7: mineral wool - comparison between analytical and numerical heat flux density fluctuations for six airflow conditions: (a) airtight and $0.001 \mathrm{~m} / \mathrm{s}$ at $x=0$, (b) airtight and $0.001 \mathrm{~m} / \mathrm{s}$ at $x=L$, (c) 0.003 and $0.006 \mathrm{~m} / \mathrm{s}$ at $x=0$, (d) 0.003 and $0.006 \mathrm{~m} / \mathrm{s}$ at $x=L$, (e) 0.009 and $0.012 \mathrm{~m} / \mathrm{s}$ at $x=0$, (f) 0.009 and $0.012 \mathrm{~m} / \mathrm{s}$ at $x=$ L. Numerical simulations performed with $\Delta x=0.001 \mathrm{~m}$ and $\Delta t=3600 \mathrm{~s}$.

The mineral wool simulations show the same trend already found with the no fines concrete, with a significantly higher dependency on the airflow velocity: while at low velocity the outdoor and indoor heat fluxes are similar, as shown in Figure 7(a) and (b) (kindly note the difference between the two ordinate axes range), a slight increase in $u_{f}$ quickly reduces the heat exchange through the outdoor surface, to almost neglectable values, while rapidly increases the one through the indoor surface. This effect is the direct consequence of the temperature distributions represented in Figure 5.

Moreover, the tendency of the numerical model to underestimate the indoor heat flux amplitude with growing airflow velocity, already observed with the no fines concrete domain, is exacerbated, with a clear discrepancy at higher speeds. Again, this can be due to the approximation error introduced by the two-points scheme used to calculate temperature space-derivative, disregarding the curvature between the two points 
considered, in an area characterized by a high temperature gradient, leading to an even greater error than the one qualitatively observed for the capacitive material.

$$
\Phi \mathrm{T} \text { error (no-fines concrete) 里 } \mathrm{T} \text { error (mineral wool) }
$$
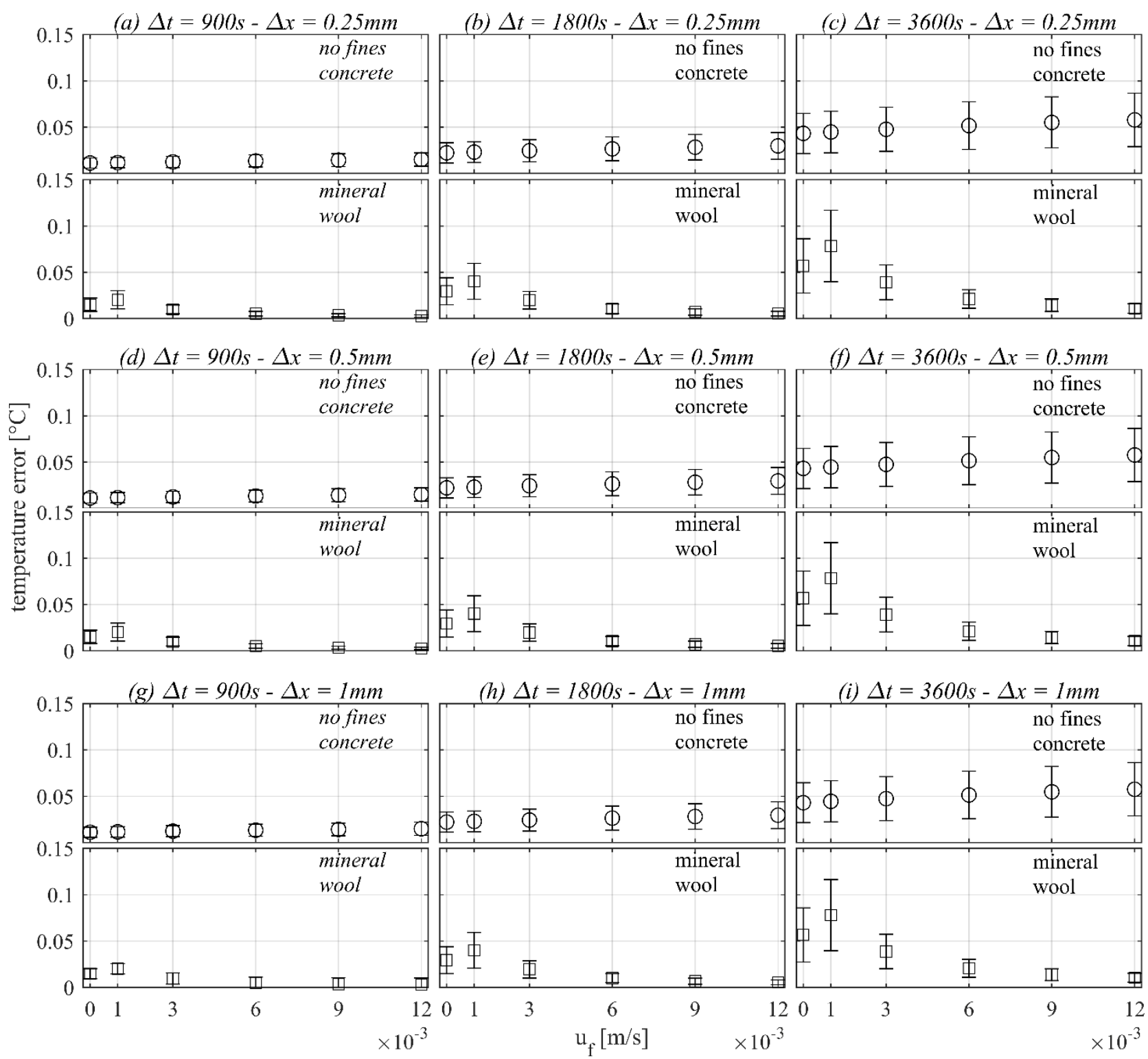

Figure 8: simulation error related to temperature distribution and variation for no fines concrete and mineral wool, calculated for every combination of space grid size $\Delta x(0.001 \mathrm{~m}, 0.0005 \mathrm{~m}$ and $0.00025 \mathrm{~m})$ and timestep $\Delta \mathrm{t}(3600 \mathrm{~s}, 1800 \mathrm{~s}$ and $900 \mathrm{~s}$ ) as a function of airflow velocity $u_{f}$.

The numerical results presented in Figure 4 and Figure 5, along with the corresponding analytical references, are used to perform a sensitivity analysis on the space and time discretization parameters, as previously stated, through the calculation of the average simulation error, also as a function of airflow velocity. Namely, the simulation error is here defined as the absolute value of the difference between the simulated quantity, either temperature or heat flux density, and the analytically calculated one at any given position or time.

Figure 8 shows the temperature error, averaged over the $x$ and $t$ coordinates, related to both no fines concrete and mineral wool: it is possible to observe that among all the combinations of discretization parameters, the worst average error is within $0.1{ }^{\circ} \mathrm{C}$. The error is also strongly dependent on the timestep, with an almost linear improvement achieved when this parameter is reduced from $3600 \mathrm{~s}$ to $900 \mathrm{~s}$, while no relevant effect is registered when $\Delta \mathrm{x}$ is reduced. Therefore, in order to improve the algorithm performance, it appears more efficient to refine the timestep then the space grid size. 

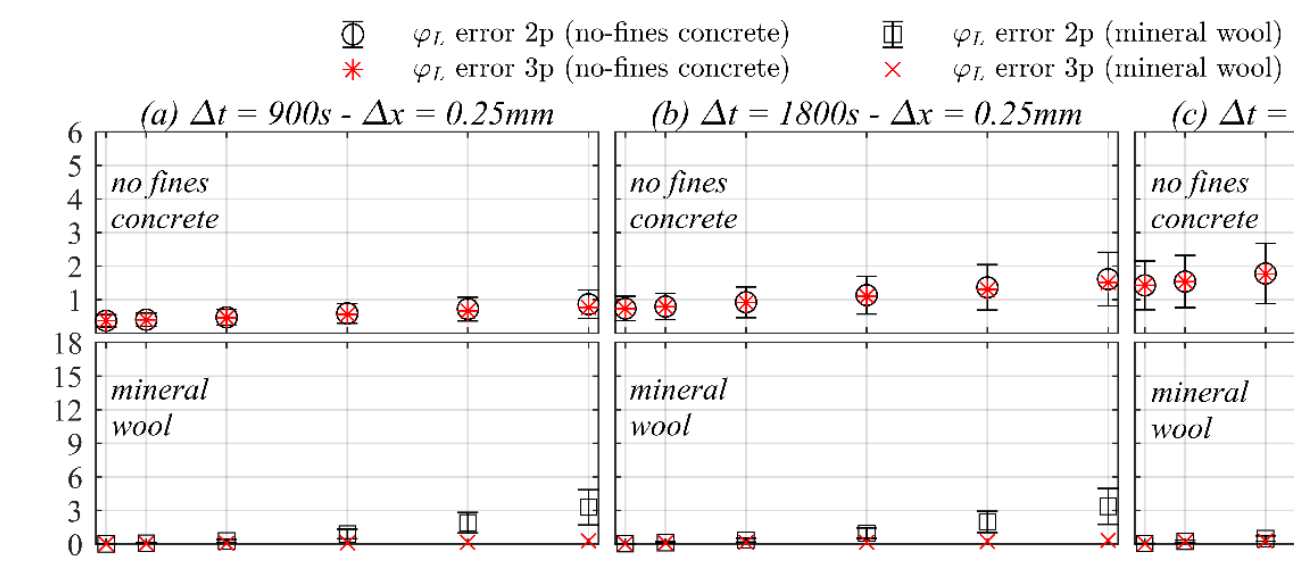

(b) $\Delta t=1800 \mathrm{~s}-\Delta x=0.25 \mathrm{~mm}$

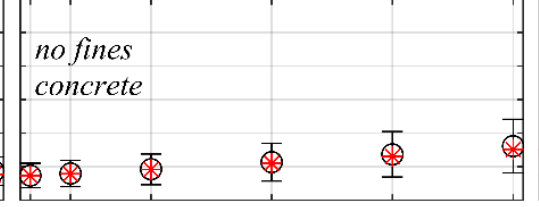

(c) $\Delta t=3600_{\mathrm{s}}-\Delta x=0.25 \mathrm{~mm}$

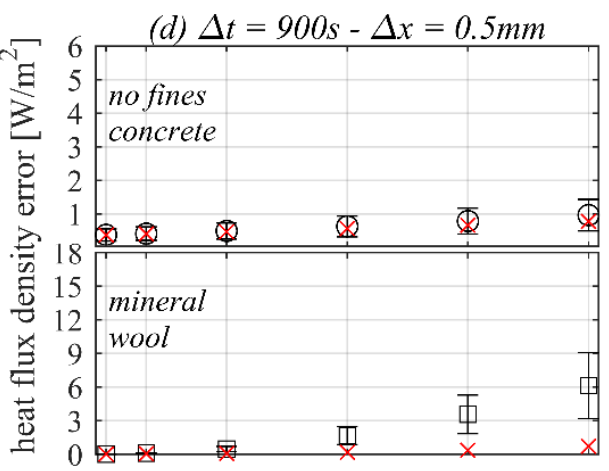

(e) $\Delta t=1800 \mathrm{~s}-\Delta x=0.5 \mathrm{~mm}$
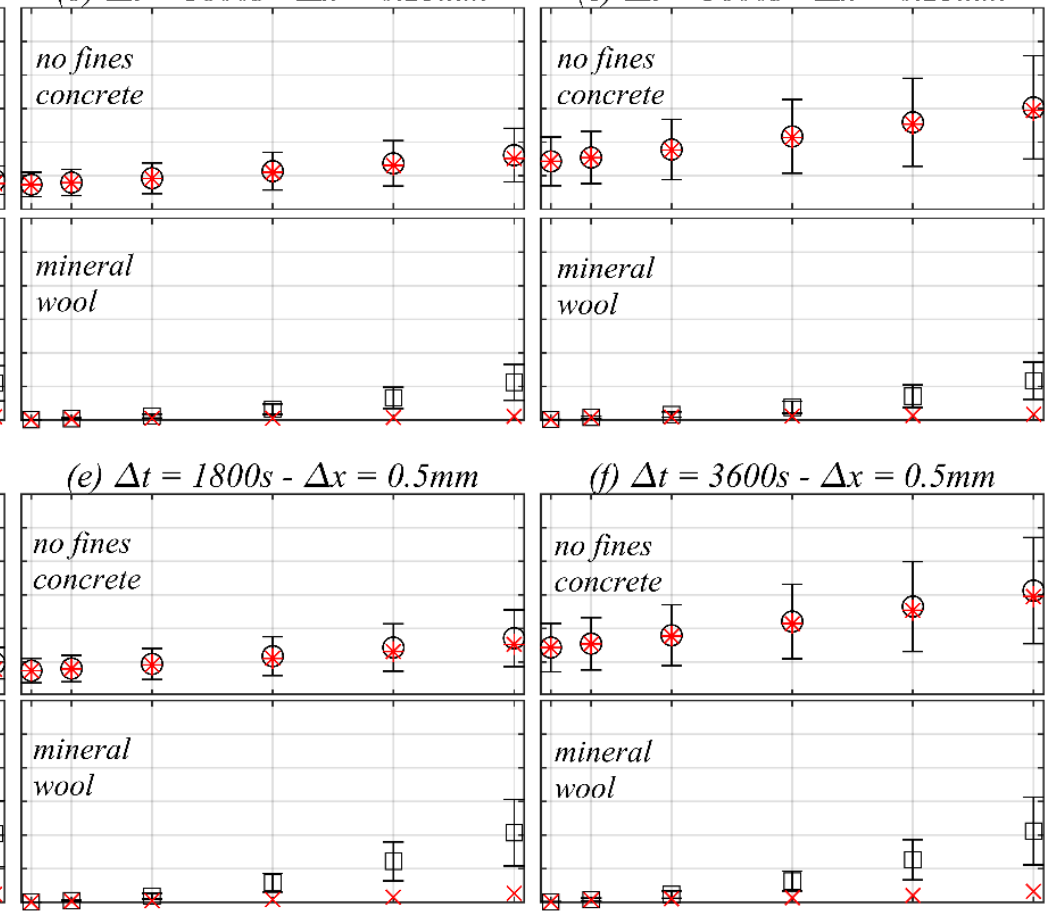

(f) $\Delta t=3600 \mathrm{~s}-\Delta x=0.5 \mathrm{~mm}$

(g) $\Delta t=900 \mathrm{~s}-\Delta x=1 \mathrm{~mm}$

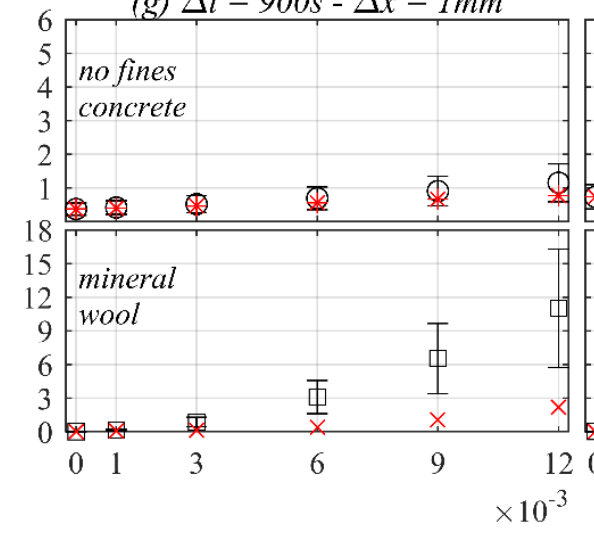

(h) $\Delta t=1800 \mathrm{~s}-\Delta x=1 \mathrm{~mm}$
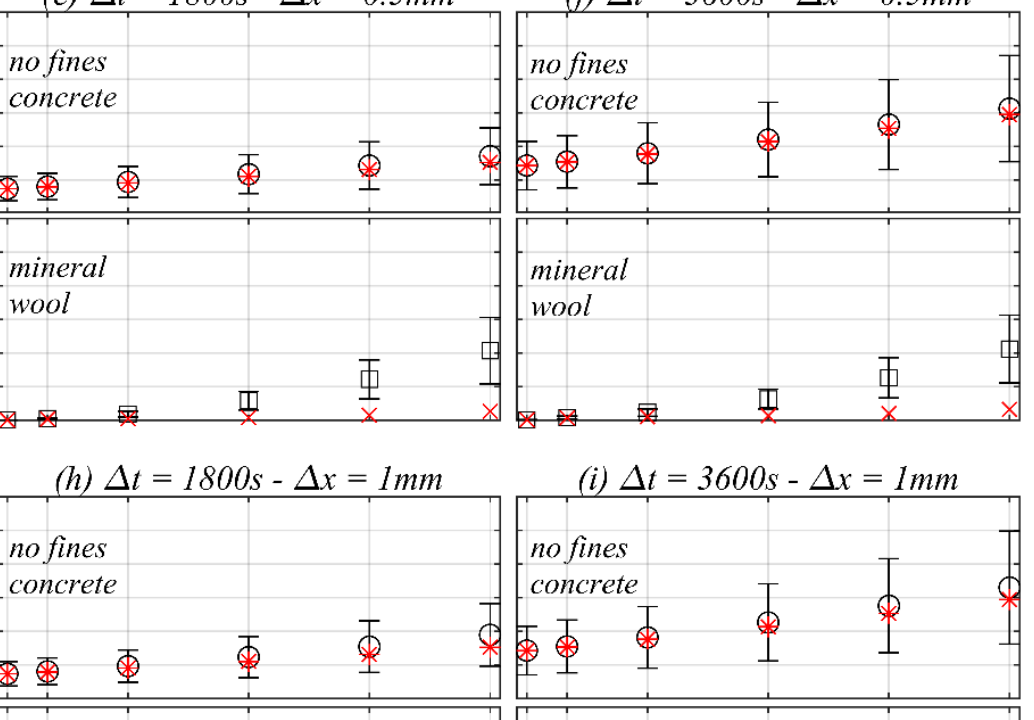

(i) $\Delta t=3600 \mathrm{~s}-\Delta x=1 \mathrm{~mm}$

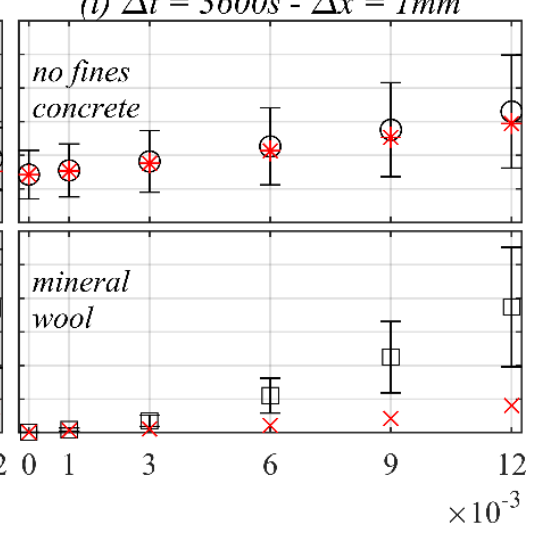

Figure 9: simulation error related to heat flux density variation at indoor surface for no fines concrete and mineral wool, calculated for every combination of space grid size $\Delta x(0.001 \mathrm{~m}, 0.0005 \mathrm{~m}$ and $0.00025 \mathrm{~m})$ and timestep $\Delta \mathrm{t}(3600 \mathrm{~s}, 1800 \mathrm{~s}$ and $900 \mathrm{~s}$ ) as a function of airflow velocity $u_{f}$. A comparison between 2-points and 3-points schemes is provided.

As far as materials are concerned, they both show the same dependency on discretization parameters. However, the effect of airflow velocity on the simulation error appears to be opposite: while for the capacitive material this quantity grows with the velocity, with the resistive one it suddenly grows when the advective component is activated and progressively drops when the airflow is increased, with the worst performance registered at $\Delta \mathrm{x}=0.001 \mathrm{~m}, \Delta \mathrm{t}=3600 \mathrm{~s}$ and $\mathrm{u}_{\mathrm{f}}=0.001 \mathrm{~m} / \mathrm{s}$ corresponding to an error of $0.198^{\circ} \mathrm{C}$ ( $0.65 \%$ of the reference) at $\mathrm{t}=17 \mathrm{~h}$ in the middle of the domain. This finding might be related to the way in which the temperature distribution reacts to the advective component in the two different materials. In general, the numerical scheme seems to encounter more difficulties in reproducing any curvature in temperature distribution, hence the bigger discrepancy between numerical and analytical results. According to this hypothesis, the distributed curvature involving the whole domain found in the no fines concrete at any airflow speed (Figure 4) and in the mineral wool at low speed (Figure 5(b) and (c)) leads to bigger average errors than the almost flat distribution followed by a steep concentrated gradient found in the mineral wool for $u_{f} \geq 0.006 \mathrm{~m} / \mathrm{s}$. Finally, these findings are coherent with those presented in (Ascione et al., 2015), where the time-dependent validation is performed considering $\Delta x=0.002 \mathrm{~m}$ and $\Delta \mathrm{t}=900 \mathrm{~s}$, with an airflow velocity 
of $5 \mathrm{~m} / \mathrm{h}(0.0014 \mathrm{~m} / \mathrm{s}$ approximately) and a maximum numerical error between $1.3 \%$ and $3.8 \%$, depending on the timestamp, is found.

As far as the heat flux density at the indoor surface is concerned (Figure 9), both materials feature a growing simulation error with increasing airflow speed. Moreover, in general terms, the magnitude of such discrepancy is significantly smaller in the no fines concrete than in the mineral wool (roughly by a factor 3 in the worse conditions), especially at higher fluid velocities. This is due to the steeper temperature gradient at the surface found in the resistive material. This difference is also mirrored by the performance dependency on the discretization parameters: while the no fines concrete domain seems to be affected only by the timestep, with no effect of $\Delta x$ on the outcomes, the insulating material is more sensitive on the space grid size. Going more in detail, the refinement of the time discretization improves the calculation of the temperature distribution, as previously discussed (Figure 8). On the other end, the space grid refinement improves the local derivative calculation through the incremental ratio, which is more effective where temperature gradient is steep: as an example, the average heat flux density error calculated for the mineral wool at $0.012 \mathrm{~m} / \mathrm{s}$ goes from around $12 \mathrm{~W} / \mathrm{m}^{2}$ to around $3 \mathrm{~W} / \mathrm{m}^{2}$ when $\Delta x$ goes from $0.001 \mathrm{~m}$ to $0.00025 \mathrm{~m}$.

This last consideration is also valid when the effect of the numerical scheme used to calculate heat flux density is considered: if the gradient is small, the choice of the 3-points scheme presented in Eq. (16) over the 2-points one (Eq.(15)) does not present significant improvements, as the case of the no fines concrete shows. Instead, when the local temperature space derivative is great, the use of Eq. (16) to calculate the local heat flux density provides better performances: considering the mineral wool simulation at $0.012 \mathrm{~m} / \mathrm{s}$, going from the simple 2-points scheme to the 3-points one drops the simulation error from around $12 \mathrm{~W} / \mathrm{m}^{2}$ to around $3 \mathrm{~W} / \mathrm{m}^{2}$, which is equivalent to the one observed with the refinement of the space discretization.

Table 5: computational time evaluated for no fines concrete and mineral wool domains at several combinations of discretization parameters when sinusoidal steady periodic boundary conditions are applied.

\begin{tabular}{lcccccc}
\hline \multicolumn{1}{c}{$\Delta \mathrm{t}[\mathrm{s}]$} & \multicolumn{2}{c}{900} & \multicolumn{2}{c}{1800} & \multicolumn{2}{c}{3600} \\
\cline { 2 - 7 }$\Delta \mathrm{x}[\mathrm{m}]$ & $\begin{array}{c}\text { no fines } \\
\text { concrete }\end{array}$ & $\begin{array}{c}\text { mineral } \\
\text { wool }\end{array}$ & $\begin{array}{c}\text { no fines } \\
\text { concrete }\end{array}$ & $\begin{array}{c}\text { mineral } \\
\text { wool }\end{array}$ & $\begin{array}{c}\text { no fines } \\
\text { concrete }\end{array}$ & $\begin{array}{c}\text { mineral } \\
\text { wool }\end{array}$ \\
\hline 0.00025 & $2.469 \mathrm{~s}$ & $2.430 \mathrm{~s}$ & $1.190 \mathrm{~s}$ & $1.245 \mathrm{~s}$ & $0.646 \mathrm{~s}$ & $0.643 \mathrm{~s}$ \\
0.0005 & $1.552 \mathrm{~s}$ & $1.493 \mathrm{~s}$ & $0.772 \mathrm{~s}$ & $0.782 \mathrm{~s}$ & $0.417 \mathrm{~s}$ & $0.448 \mathrm{~s}$ \\
0.001 & $1.284 \mathrm{~s}$ & $1.283 \mathrm{~s}$ & $0.665 \mathrm{~s}$ & $0.672 \mathrm{~s}$ & $0.360 \mathrm{~s}$ & $0.364 \mathrm{~s}$ \\
\hline
\end{tabular}

Finally, dealing with computational cost, it has been observed a substantial independence on the airflow velocity and the material involved, while the only relevant parameters to this purpose are the timestep and the space grid size, that affect the number of grid nodes and timestamps considered by the numerical algorithm. As shown in Table 5, it is possible to observe that going from $\Delta x$ equal to $0.001 \mathrm{~m}$ to $0.0005 \mathrm{~m}$ causes a 15 - $20 \%$ increase in computational time, and a further refinement is characterized by an additional 50-60 \% increase. At the same time, the computational cost growth related to timestep refinement is almost linear, since it doubles on average at every refining step.

Moreover, it is useful to highlight the substantial difference between the computational costs measured for the reference parameters $(\Delta x=0.001 \mathrm{~m}$ and $\Delta t=3600 \mathrm{~s})$ and the refined ones $(\Delta x=0.00025 \mathrm{~m}$ and $\Delta t=900 \mathrm{~s}$ ), with a resulting increase of this quantity by a ratio bigger than 6 , which implies a substantial increase of the time required to simulate the yearly building performance, if this algorithm is integrated into a building simulation software for BW design purposes.

This first part of the work presented in this paper shows that the numerical model investigated is able to adequately simulate BW components, even when the standard discretization parameters are used, and can be considered validated. Moreover, it is demonstrated that the domain response to the advective component of the energy balance is strongly affected by the material it is composed of, and such behavior imposes different consideration about the discretization parameters choice. Timestep refinement seems to be the most effective strategy to improve the resulting temperature distribution across the domain; however, if an insulating material is involved and the indoor bound heat flux density is a relevant quantity for a given study, a significant improvement can be achieved both refining the spatial grid and switching from a 2-points to a 3-points approximation of the space derivative in the heat flux equation. 


\subsubsection{Fourier series boundary conditions}

The second phase of this work is a further comparison between numerical and analytical results obtained with more complex outdoor boundary conditions, achieved through superposition of harmonics with progressively smaller period.

Going more in detail, the Milan area climate data from the Italian technical standard (UNI/TR 10349-2:2016) are used. Starting from the design external air temperature fluctuation $T_{\text {air }}(t)$ and the solar irradiance for a vertical surface exposed to North at a latitude of $45^{\circ} \mathrm{N} G_{N}(t)$, hourly values of a combined boundary condition are obtained as follows:

$$
T_{0}(t)=T_{\text {air }}(t)+\frac{a_{w}}{h_{c r, \text { ext }}} G_{N}(t)
$$

where $a_{w}$ is the solar absorptivity of the wall surface and $h_{c r}$ is the external convective-radiative surface heat transfer coefficient, assumed equal to 0.6 and $25 \mathrm{~W} /\left(\mathrm{m}^{2} \cdot \mathrm{K}\right)$ respectively. The internal boundary condition $T_{L}(t)$ is instead kept constant at a value of $26^{\circ} \mathrm{C}$, similarly to what has been done in the first phase.

In order to be able to use the discrete hourly values for the external boundary condition, this array of 24 data of $T_{0}(t)$ is processed using the Matlab ${ }^{\circledR}$ Curve Fitting Toolbox through Fourier series to obtain the parameters for Eq. (4). The interpolating equation involves summations of $n=8$ terms, whose parameters are reported in Table 6.

Table 6: parameters of the Fourier decomposition of the external boundary condition, according to Eq. (4).

\begin{tabular}{cccccccccc} 
& & $\boldsymbol{k}=\mathbf{1}$ & $\boldsymbol{k}=\mathbf{2}$ & $\boldsymbol{k}=\mathbf{3}$ & $\boldsymbol{k}=\mathbf{4}$ & $\boldsymbol{k}=\mathbf{5}$ & $\boldsymbol{k}=\mathbf{6}$ & $\boldsymbol{k}=\mathbf{7}$ & $\boldsymbol{k}=\mathbf{8}$ \\
\hline $\bar{T}_{0}\left[{ }^{\circ} \mathrm{C}\right]$ & 27.11 & - & - & - & - & - & - & - & - \\
$\omega_{k}[\mathrm{rd} / \mathrm{s}]$ & - & $7.27 \cdot 10^{-5}$ & $1.45 \cdot 10^{-4}$ & $2.18 \cdot 10^{-4}$ & $2.91 \cdot 10^{-4}$ & $3.64 \cdot 10^{-4}$ & $4.36 \cdot 10^{-4}$ & $5.09 \cdot 10^{-4}$ & $5.82 \cdot 10^{-4}$ \\
$\Delta T_{0, a, k}\left[{ }^{\circ} \mathrm{C}\right]$ & - & 5.478 & 0.2519 & 0.3611 & 0.808 & 0.2202 & 0.573 & 0.1085 & 0.37 \\
$\Delta T_{0, b, k}\left[{ }^{\circ} \mathrm{C}\right]$ & - & 4.618 & 1.002 & 0.007069 & $6.4 \cdot 10^{-6}$ & 0.005212 & 0.01001 & 0.01158 & $6.2 \cdot 10^{-6}$ \\
$\psi_{0, a, k}[\mathrm{rd}]$ & - & 3.142 & 3.142 & 0 & 0 & 3.142 & 3.142 & 0 & 0 \\
$\psi_{0, b, k}[\mathrm{rd}]$ & - & 3.142 & 0 & 0 & 3.142 & 0 & 0 & 0 & 3.142 \\
\hline
\end{tabular}

The resulting boundary condition for the outer surface is therefore calculated as a superposition of the steady state component $\bar{T}_{0}$ and the summations of the $n=8$ sine and cosine summation terms, as shown in Figure 10. It is possible to observe that the superposition of temperature and solar radiation variations leads to a less regular fluctuation of the boundary condition than the one investigated during the first validation phase.

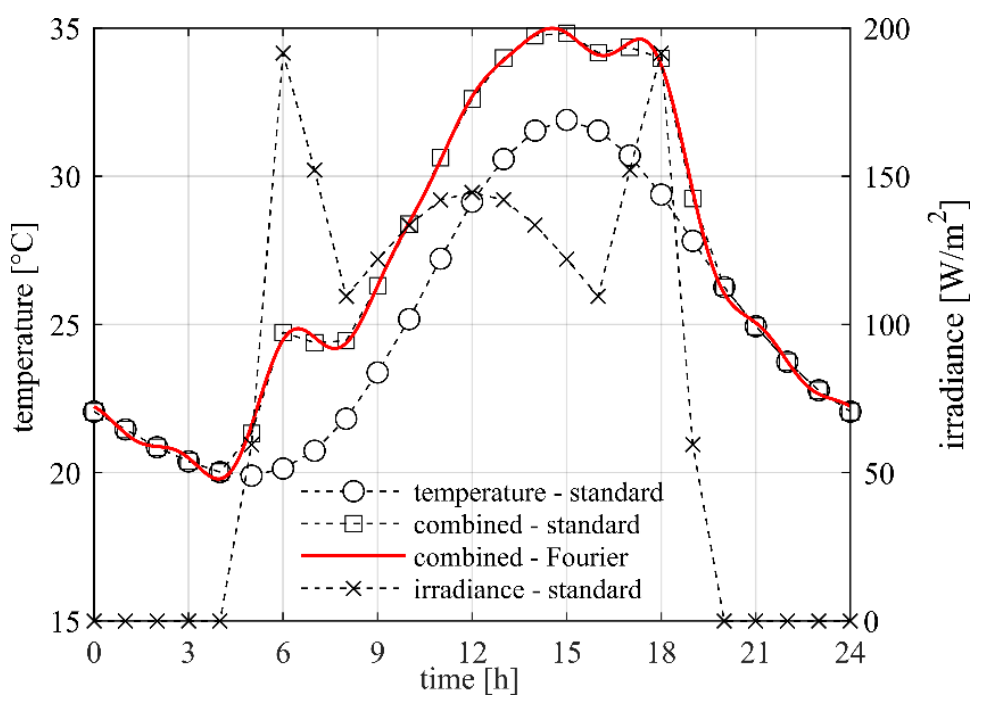

Figure 10: climate data from the Italian technical standard and temperature-radiation combined boundary condition.

In this phase, numerical and analytical calculations are performed considering the same materials and airflow conditions assumed in the previous phase. As far as discretization parameters are concerned, only the two extremes of the spatial grid dimension $(0.00025 \mathrm{~m}$ and $0.001 \mathrm{~m})$ are considered, along with the extreme timesteps (900 s and $3600 \mathrm{~s}$ ), plus an even smaller timestep (600 s): it has been previously observed that the timestep refinement provides the more significant improvements, and the aim is to investigate the costbenefit ratio of refining this parameter even further. 


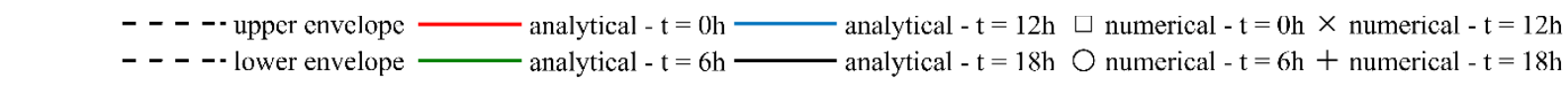

(a) no fines concrete-airtight
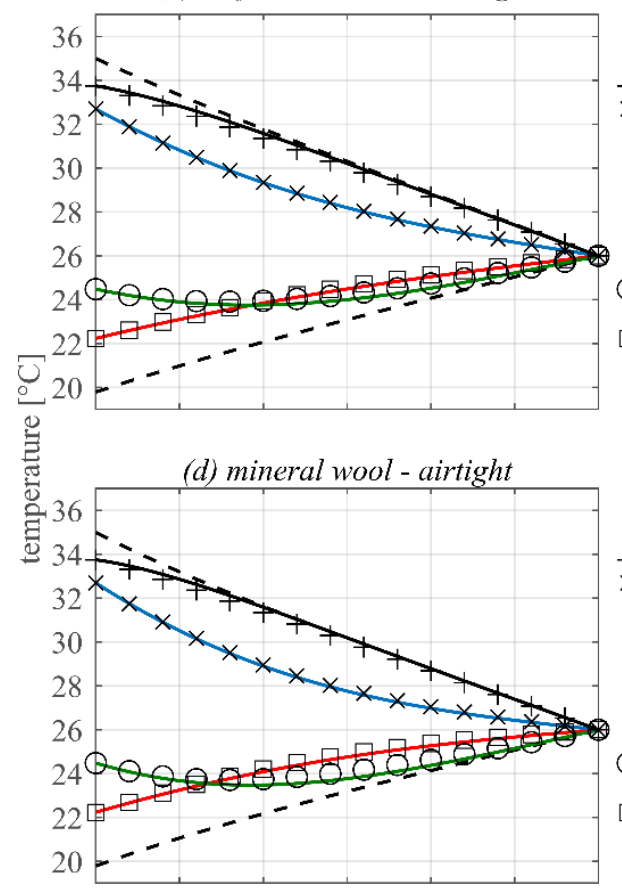

(b) no fines concrete $-u_{f}=0.001 \mathrm{~m} / \mathrm{s}$

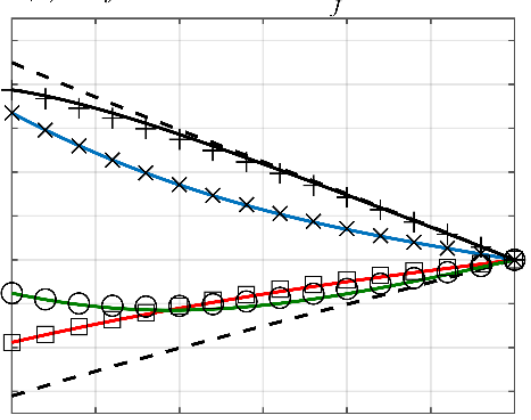

(e) mineral wool $-u_{f}=0.001 \mathrm{~m} / \mathrm{s}$

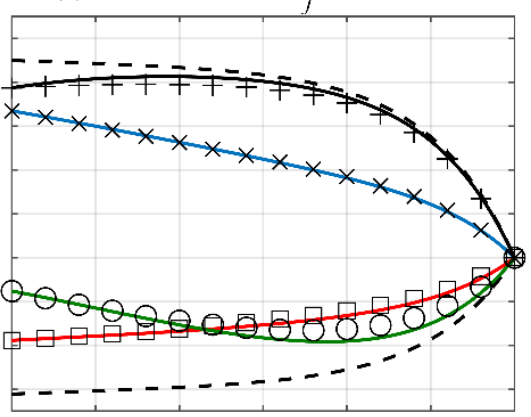

(c) no fines concrete $-u_{f}=0.012 \mathrm{~m} / \mathrm{s}$

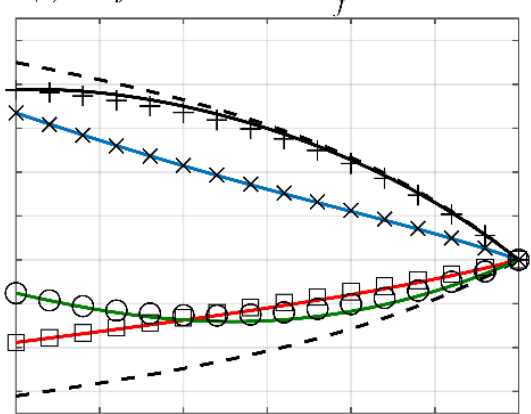

(f) mineral wool $-u_{f}=0.012 \mathrm{~m} / \mathrm{s}$

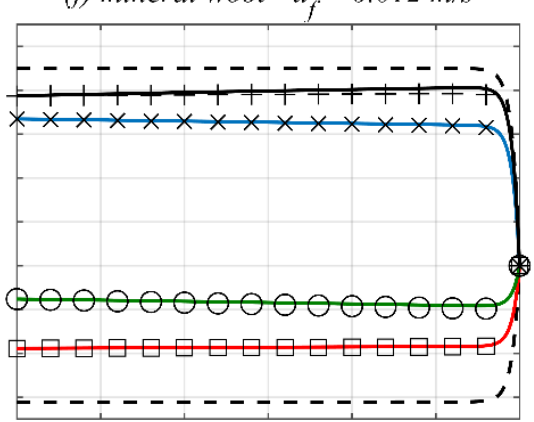

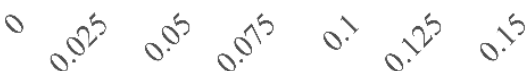

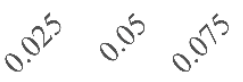

$\mathrm{x}[\mathrm{m}]$

Figure 11: comparison between analytical and numerical temperature distributions at four timestamps ( $t=0 \mathrm{~h}, t=6 \mathrm{~h}$, $t=12 \mathrm{~h}$ and $t=18 \mathrm{~h}$ ) for the no fines concrete domain at three airflow conditions (a) airtight, (b) $0.001 \mathrm{~m} / \mathrm{s}$, (c) 0.012 $\mathrm{m} / \mathrm{s}$ and for the mineral wool domain at three airflow conditions (d) airtight, (e) $0.001 \mathrm{~m} / \mathrm{s},(f) 0.012 \mathrm{~m} / \mathrm{s}$. Numerical simulations performed with $\Delta x=0.001 \mathrm{~m}$ and $\Delta t=3600 \mathrm{~s}$.

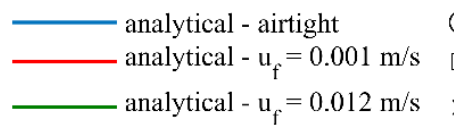

(a) no fines concrete

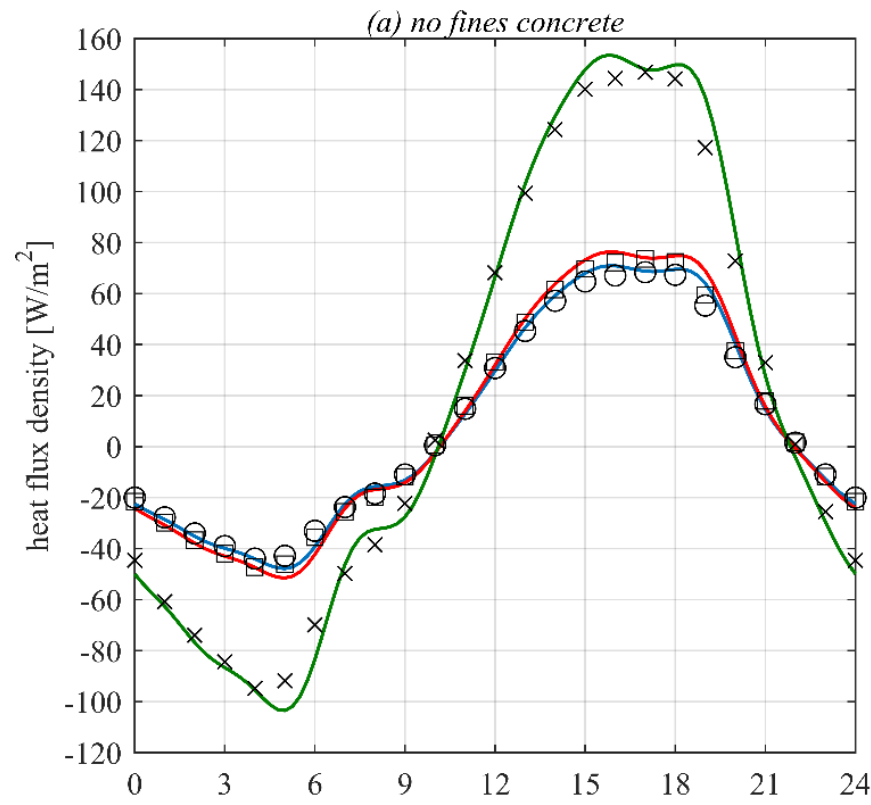

numerical - airtight numerical $-\mathrm{u}_{\mathrm{f}}=0.001 \mathrm{~m} / \mathrm{s}$ numerical $-u_{\mathrm{f}}=0.012 \mathrm{~m} / \mathrm{s}$

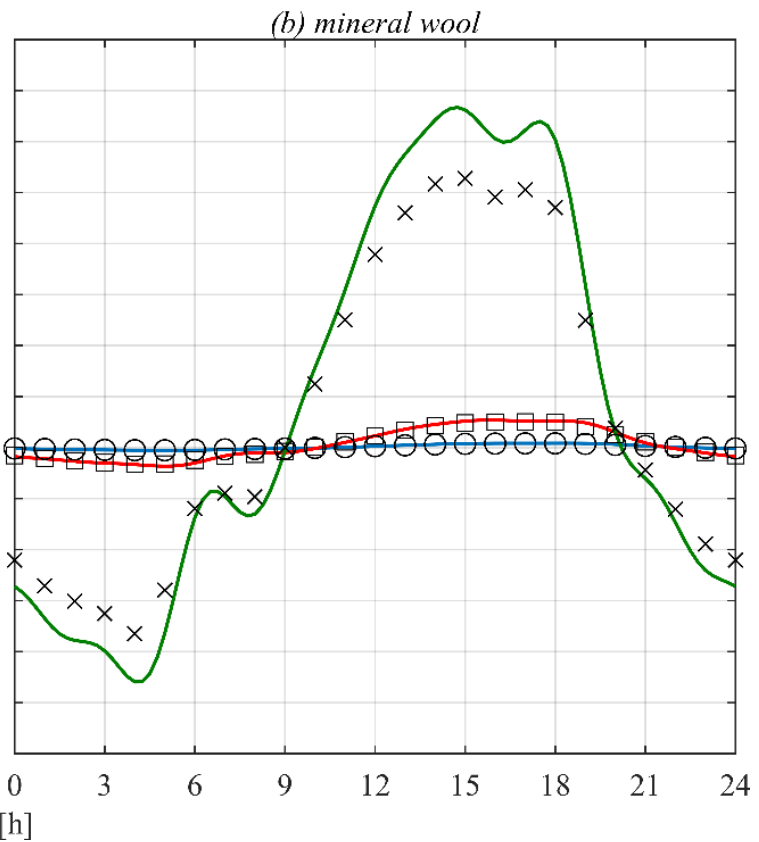

Figure 12: comparison between (a) no fines concrete and (b) mineral wool analytical and numerical heat flux density fluctuations at $x=L$ for three airflow conditions: airtight, $0.001 \mathrm{~m} / \mathrm{s}$ and $0.012 \mathrm{~m} / \mathrm{s}$. Numerical simulations performed with $\Delta x=0.001 \mathrm{~m}$ and $\Delta t=3600 \mathrm{~s}$. 
Actually, it can be noted that the smallest timestep previously considered, namely $900 \mathrm{~s}$, should be enough to adequately sample the $8^{\text {th }}$ order harmonic of the external boundary condition, which has a period of $10800 \mathrm{~s}$; therefore, it is expected that a further refinement should not provide a significant improvement.

Considering now the outcomes of this analysis, the agreement between numerical and analytical data for both temperature distributions and heat flux density fluctuations at the edges of the domain is qualitatively similar to that already observed under sinusoidal outdoor boundary conditions, whether the material considered is the no fines concrete or the mineral wool.

For the sake of brevity, Figure 11 and Figure 12 show the temperature distributions and the surface heat flux density fluctuations at the inside face for both materials at three airflow levels (airtight, $0.001 \mathrm{~m} / \mathrm{s}$ and $0.012 \mathrm{~m} / \mathrm{s}$ ) as an example. Simulated and calculated temperatures appear to be coherent at every velocity considered, while the heat flux density shows significant discrepancies only at $0.012 \mathrm{~m} / \mathrm{s}$. Since this outcome has already been discussed in the previous phase, it will not be analyzed further.

$\Phi \quad \mathrm{T}$ error (no-fines concrete) $\quad$ 里 $\mathrm{T}$ error (mineral wool)

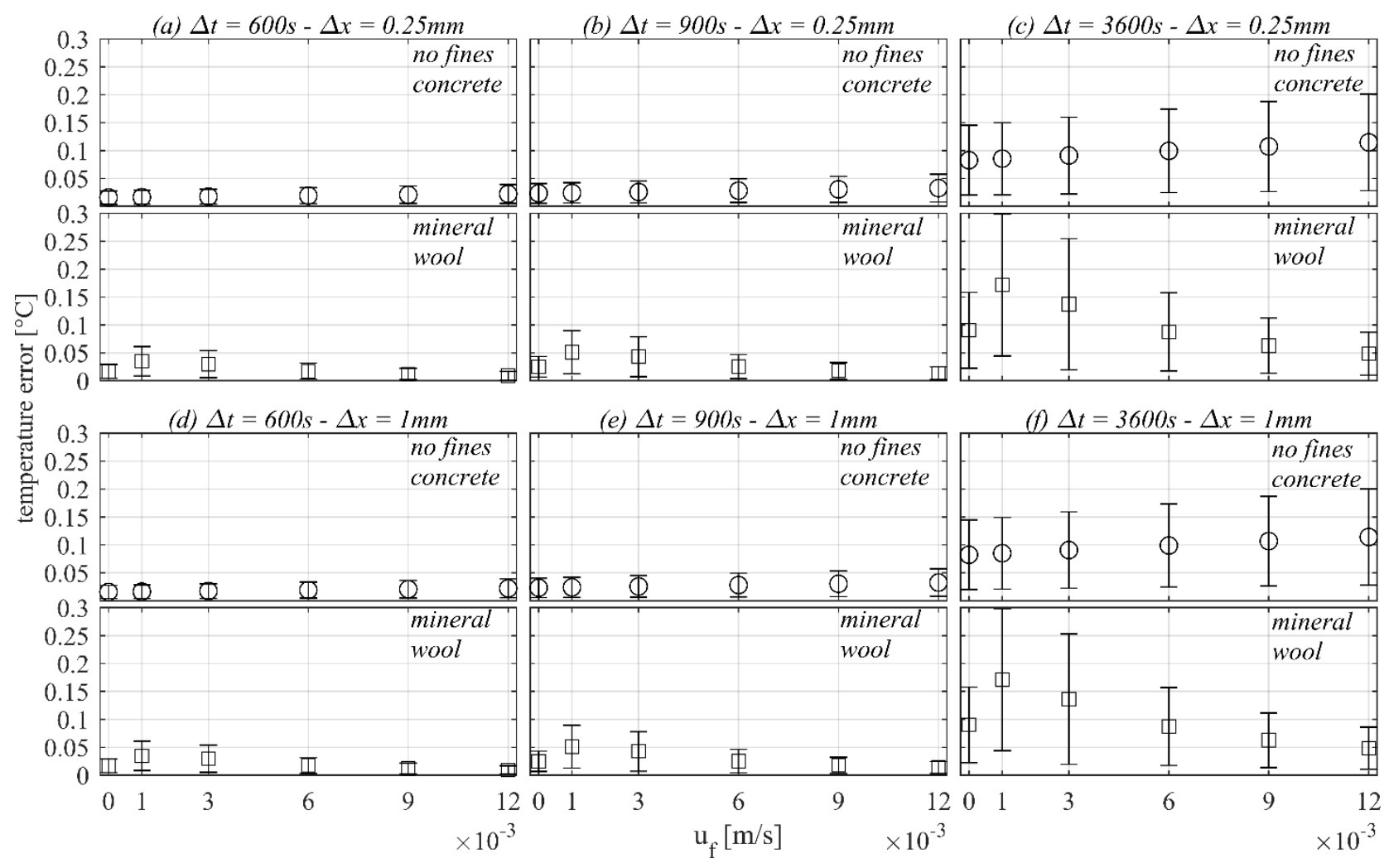

Figure 13: simulation error related to temperature distribution for no fines concrete and mineral wool, calculated for every combination of space grid dimension $\Delta x(0.001 \mathrm{~m}$ and $0.00025 \mathrm{~m})$ and timestep $\Delta t(3600 \mathrm{~s}, 900 \mathrm{~s}$ and $600 \mathrm{~s})$ as a function of airflow velocity $u_{f}$.

As far as the average simulation error related to temperature is concerned, Figure 13 shows its dependency on the airflow velocity, the discretization parameters and the material constituting the domain. If compared to Figure 8 , it is possible to observe that, whenever similar settings are used, the complicated outdoor boundary condition is more challenging to the numerical algorithm than the simple sine fluctuations previously considered: it is possible to observe that the error is almost doubled both in terms of average value and standard deviation for almost every condition considered. Therefore, a generally worse performance in simulating components subjected to real climatic outdoor conditions, if compared to simple steady periodic sinusoidal variations, might be expected.

Furthermore, the dependencies on the airflow velocity for the two materials show the same trends previously observed, with a continuous growth for the capacitive material and a pick value at the activation of the advective component followed by a progressive drop for the resistive material. 
Finally, even though a further refinement of the timestep from $900 \mathrm{~s}$ to $600 \mathrm{~s}$ provides a $32 \%$ reduction of the simulations error in every condition considered, its absolute magnitude is minimal both in terms of average value and standard deviation: indeed, the worst result observed at $900 \mathrm{~s}$ (at $\mathrm{u}_{\mathrm{f}}=0.001 \mathrm{~m} / \mathrm{s}$, regardless of the $\Delta \mathrm{x}$ value) are an average error of $0.051^{\circ} \mathrm{C}$ and a standard deviation of $0.038^{\circ} \mathrm{C}$ and their values drop to $0.035^{\circ} \mathrm{C}$ and $0.026{ }^{\circ} \mathrm{C}$ respectively at $600 \mathrm{~s}$ timestep. This means that the improvement provided is small and the opportunity for such a refinement has to be carefully evaluated according to the purposes of the simulation, taking into account also the consequent increase in computational cost.

$$
\begin{array}{cccc}
\Phi & \varphi_{L} \text { error } 2 \mathrm{p} \text { (no-fines concrete) } & \text { 里 } & \varphi_{L} \text { error } 2 \mathrm{p} \text { (mineral wool) } \\
* & \varphi_{L} \text { error } 3 \mathrm{p} \text { (no-fines concrete) } & \times & \varphi_{L} \text { error } 3 \mathrm{p} \text { (mineral wool) }
\end{array}
$$

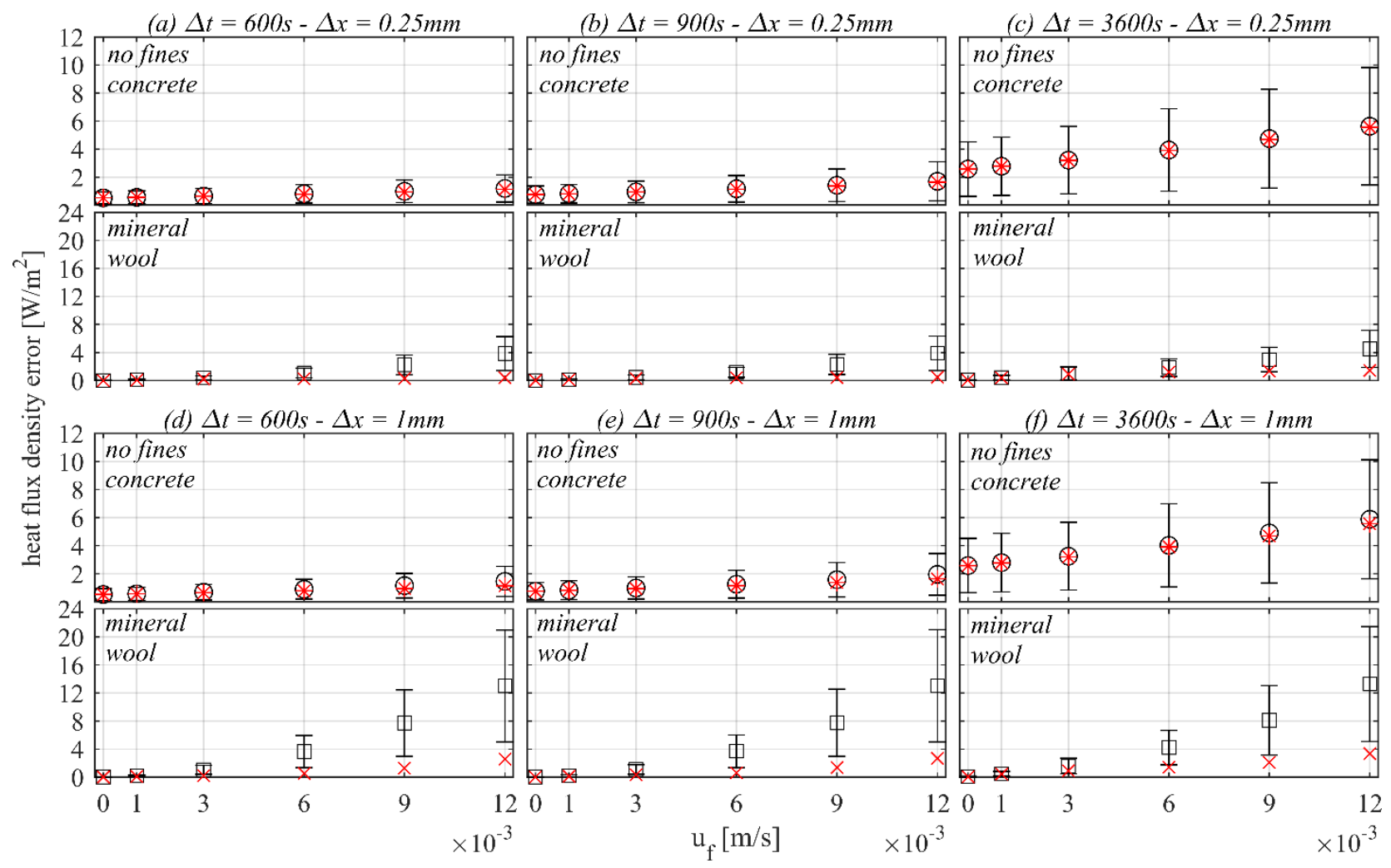

Figure 14: simulation error related to heat flux density variation at indoor surface for no fines concrete and mineral wool, calculated for every combination of space grid dimension $\Delta x(0.001 \mathrm{~m}$ and $0.00025 \mathrm{~m})$ and timestep $\Delta t$ ( $3600 \mathrm{~s}$, $900 \mathrm{~s}$ and $600 \mathrm{~s})$ as a function of airflow velocity $u_{f}$. A comparison between 2-points and 3-points schemes is provided.

The discrepancy between numerical and analytical heat flux density at the indoor surface described in Figure 14 shows the same trends already found with the simple sinusoidal outdoor boundary condition (Figure 9). First, the error found for the insulating material using the 2-points equation is generally double the one for the no fines concrete, due to the larger local temperature gradient. Second, when the discretization parameters are concerned, the capacitive material performance is substantially independent on the spatial grid dimension, while this quantity is the only relevant one for the mineral wool. Finally, as observed in the first phase of this work, the choice of the 3-points scheme for temperature spatial derivative provides a large improvement over the 2-points one whenever steep gradients are in place, like in the case of a resistive material crossed by a relatively high velocity airflow.

As observed previously when dealing with temperature distributions, a reduction from a timestep of $900 \mathrm{~s}$ to a $600 \mathrm{~s}$ one does not provide significant improvements in terms of discrepancy between numerical and analytical heat flux density. Concerning the no fines concrete domain, such refinement provides a $29-33 \%$ reduction of the simulation error: even though in relative terms it appears to be a large enhancement, it is minimal in absolute terms (from $1.95 \mathrm{~W} / \mathrm{m}^{2}$ to $1.46 \mathrm{~W} / \mathrm{m}^{2}$ at $0.012 \mathrm{~m} / \mathrm{s}$ of airflow velocity) if compared to the daily heat flux density fluctuation range $\left(\varphi_{\mathrm{L}}=-100 \mathrm{~W} / \mathrm{m}^{2} \div 150 \mathrm{~W} / \mathrm{m}^{2}\right)$. At the same time, if the domain consists of the insulating material, the timestep is irrelevant, and a much effective approach to improve heat 
flux density at the surface is provided by either refining the spatial grid or switching to a 3-points scheme to calculate the temperature spatial derivative.

Table 7: computational time evaluated for no fines concrete and mineral wool domains at several combinations of discretization parameters when complicated steady periodic boundary conditions are applied.

\begin{tabular}{lcccccc}
\hline$\Delta \mathrm{t}[\mathrm{s}]$ & \multicolumn{2}{c}{600} & \multicolumn{2}{c}{900} & \multicolumn{2}{c}{3600} \\
\hline \multirow{2}{*}{$\Delta \mathrm{x}[\mathrm{m}]$} & $\begin{array}{c}\text { no fines } \\
\text { concrete }\end{array}$ & $\begin{array}{c}\text { mineral } \\
\text { wool }\end{array}$ & $\begin{array}{c}\text { no fines } \\
\text { concrete }\end{array}$ & $\begin{array}{c}\text { mineral } \\
\text { wool }\end{array}$ & $\begin{array}{c}\text { no fines } \\
\text { concrete }\end{array}$ & $\begin{array}{c}\text { mineral } \\
\text { wool }\end{array}$ \\
\hline 0.00025 & $3.642 \mathrm{~s}$ & $3.690 \mathrm{~s}$ & $2.466 \mathrm{~s}$ & $2.513 \mathrm{~s}$ & $0.678 \mathrm{~s}$ & $0.665 \mathrm{~s}$ \\
0.001 & $2.064 \mathrm{~s}$ & $1.933 \mathrm{~s}$ & $1.424 \mathrm{~s}$ & $1.363 \mathrm{~s}$ & $0.404 \mathrm{~s}$ & $0.382 \mathrm{~s}$ \\
\hline
\end{tabular}

Finally, the computational costs for the group of simulations is presented in this section, according to the same principles previously presented. The data reported in Table 7, if compared to those in Table 5, show that for a given set of discretization parameters, the kind of material and the shape of the outdoor boundary conditions have no effect. Moreover, the timestep refinement from $900 \mathrm{~s}$ to $600 \mathrm{~s}$ feature the same linear increase in computational cost already observed during the first phase of this work. If this finding is considered in combination with the outcomes of the discussion about the simulation errors presented above, it is possible to state that a further refinement of the time discretization past $900 \mathrm{~s}$ does not provide a significant improvement in the accuracy of the numerical algorithm and is therefore not justified. Moreover, an additional general conclusion can be drawn: in order to define the time discretization to run a building performance simulation under realistic boundary conditions (e.g. climatic data), it might be useful to preliminary perform their frequency analysis. This allows to find the main harmonics and choose a timestep small enough to resolve the one with the smallest period that the user aims to reproduce.

\subsection{Comparison to experimental measurements}

The third part of this investigation is finally based on testing the numerical model against experimental data collected on a no fines concrete sample, as stated in Section 2.4. Going more in detail, it was arranged a series of tests performed imposing an operative temperature steady periodic sinusoidal condition in one chamber and a steady state one in the other. A $24 \mathrm{~h}$ period sinusoidal pattern is replicated in Box 1, with average temperature $26{ }^{\circ} \mathrm{C}$ and amplitude $6{ }^{\circ} \mathrm{C}$, representing the outdoor environment in Milan during summer design day. In Box 2 the operative temperature is kept stationary at $26^{\circ} \mathrm{C}$, representing an indoor summer condition for a residential or office building. These conditions are the same already used in the first phase of this work, although in this case they refer to operative temperature set point used to run the experimental tests, while there they are applied as surface temperatures. As far as airflow is concerned, five different average air velocities are tested $(0.001 \mathrm{~m} / \mathrm{s}, 0.003 \mathrm{~m} / \mathrm{s}, 0.006 \mathrm{~m} / \mathrm{s}, 0.009 \mathrm{~m} / \mathrm{s}$ and $0.012 \mathrm{~m} / \mathrm{s})$, along with a reference test without airflow (airtight) to replicate the behavior of a traditional wall as a benchmark. Data are collected every $5 \mathrm{~s}$ for a period of at least three days, in order to guarantee the achievement of the desired condition, which is assessed through the observation of the measured operative temperatures.

The validation process is then conducted as follows: surface temperatures measured in each test are filtered and interpolated using the Matlab ${ }^{\circledR}$ Curve Fitting Toolbox, to achieve analytical equations consistent with Eqs. (4) and (5) that allow to derive these quantities at every necessary time and to neglect any small fluctuation due to measurement noise. The results of the fitting process are then used as surface temperatures boundary conditions to run the numerical algorithm, along with the appropriate airflow rate value corresponding to each test. The outcomes of the numerical simulations (i.e. temperature distribution across the calculation domain and heat flux density at the inner surface) are then directly compared to the corresponding experimental data. Indeed, during each test temperature distributions across the section of the no-fines concrete slab are sampled under steady periodic boundary conditions. At the same time, heat flux density on the surface facing Box 2 is measured.

Collected data are inspected to assess the achievement of the desired experimental environment conditions: namely, a periodically recursive fluctuation for the operative temperature in Box 1 and a stationary operative temperature in Box 2. Measurements show an average control error of $-0.05{ }^{\circ} \mathrm{C} \div 0.04{ }^{\circ} \mathrm{C}$ with a standard deviation of $0.05{ }^{\circ} \mathrm{C} \div 0.13^{\circ} \mathrm{C}$, depending on the test. This means that the DAVTB facility is able to achieve the desired conditions with an acceptable level of accuracy, and the surface temperature measurements, as 
shown in Figure 15(a) and (b), can then be used to derive the boundary conditions for the simulation process later discussed. More details about the efficiency of the control algorithm are provided in (Alongi et al., 2020).
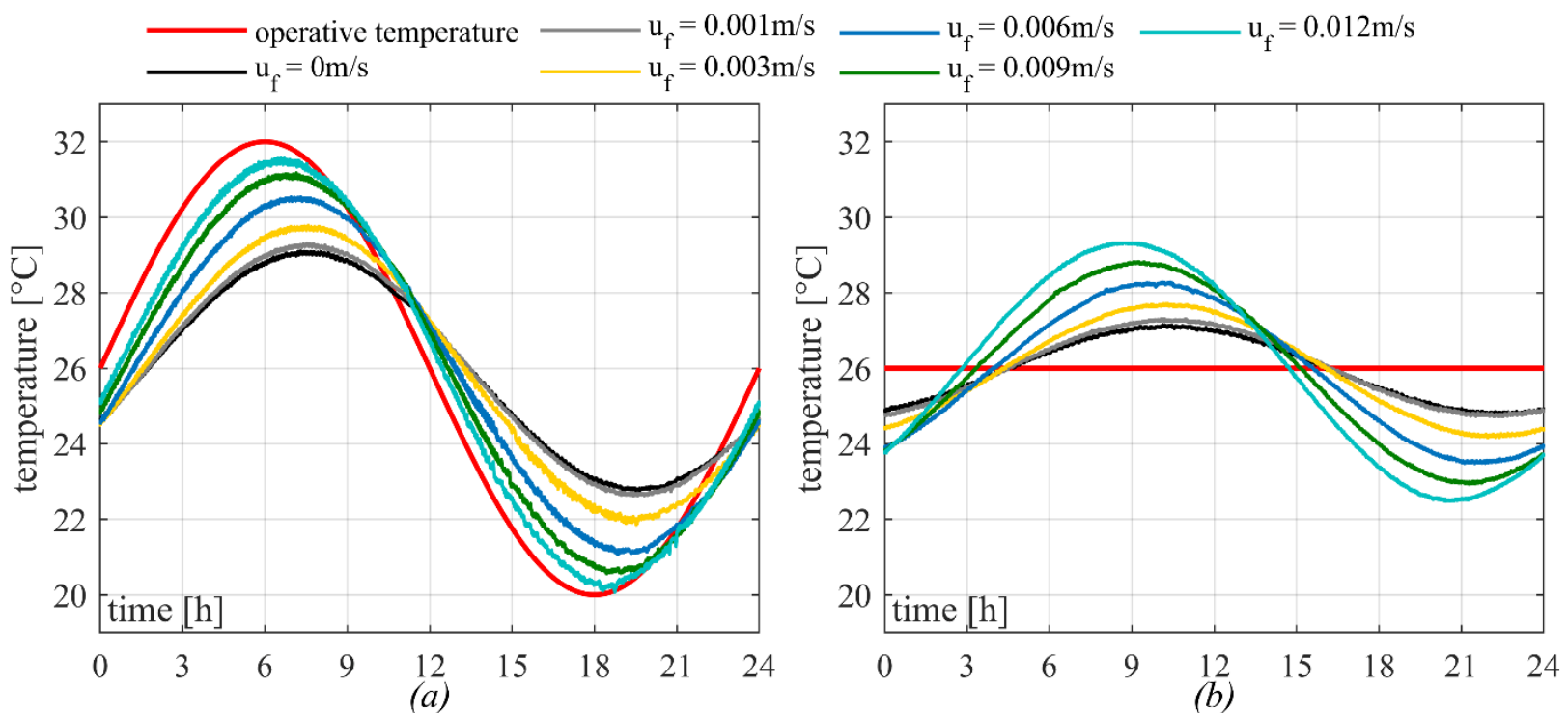

Figure 15: operative temperature (red line) and surface temperatures (other colours) measured for each test on Box 1 side (a) and on Box 2 side (b).

The achievement of the steady periodic condition is verified over the surface temperatures too, as clearly observable by the sinusoidal profiles displayed in Figure 15(a) and (b). Then, these quantities are processed using the Matlab ${ }^{\circledR}$ Curve Fitting Toolbox to obtain the parameters required in Eqs. (4) and (5) for the first order in the sine summation term (subscripts $0, b, 1$ and $L, b, 1$ ), with the assumption of the angular frequency $\omega$ equal to $7.27 \cdot 10^{-5} \mathrm{rd} / \mathrm{s}$, corresponding to a period of $24 \mathrm{~h}$. The results are summarized in Table 8.

Table 8: results of the fitting process applied on the surface temperatures measured on the Box $1\left(T_{0}\right)$ and on the Box $2\left(T_{N}\right)$ sides for each test performed.

\begin{tabular}{ccccccc} 
& \multicolumn{3}{c}{$\boldsymbol{T}_{\mathbf{0}}$ coefficients - Eq.(4) } & \multicolumn{3}{c}{$\boldsymbol{T}_{N}$ coefficients - Eq.(5) } \\
\hline $\mathbf{u}$ & $\overline{\boldsymbol{T}}_{\mathbf{0}}$ & $\Delta \boldsymbol{T}_{\mathbf{0}, \boldsymbol{b}, \mathbf{1}}$ & $\boldsymbol{\psi}_{\mathbf{0 , b}, \mathbf{1}}$ & $\overline{\boldsymbol{T}}_{\boldsymbol{L}}$ & $\Delta \boldsymbol{T}_{\boldsymbol{L}, \boldsymbol{b}, \mathbf{1}}$ & $\boldsymbol{\psi}_{\boldsymbol{L}, \boldsymbol{b}, \mathbf{1}}$ \\
{$[\mathbf{m} / \mathbf{s}]$} & {$\left[{ }^{\circ} \mathbf{C}\right]$} & {$\left[{ }^{\circ} \mathbf{C}\right]$} & {$[\mathbf{r d}]$} & {$\left[{ }^{\circ} \mathbf{C}\right]$} & {$\left[{ }^{\circ} \mathbf{C}\right]$} & {$[\mathbf{r d}]$} \\
\hline 0 & 25.91 & 3.12 & -0.423 & 25.95 & 1.15 & -1.149 \\
0.001 & 25.94 & 3.29 & -0.429 & 26.01 & 1.27 & -1.231 \\
0.003 & 25.88 & 3.84 & -0.380 & 25.94 & 1.73 & -1.103 \\
0.006 & 25.85 & 4.65 & -0.298 & 25.88 & 2.36 & -0.994 \\
0.009 & 25.88 & 5.22 & -0.211 & 25.89 & 2.90 & -0.833 \\
0.012 & 25.89 & 5.60 & -0.152 & 25.94 & 3.38 & -0.719 \\
\hline
\end{tabular}

The coefficients reported in Table 8, allow to draw some conclusions about the experimental phase of this work. First of all, as expected, all the stationary components are comparable to the desired value of $26^{\circ} \mathrm{C}$ on both sides of the sample, leading to an almost null stationary component of the heat flux density. Secondly, the growth of the airflow rate velocity leads to an increased fluctuation of both surface temperatures: as a consequence of the air motion from Box 1 to Box 2 across the sample, the operative temperature variation over time inside the first box affects the no-fines concrete slab in an increasingly relevant way.

Data collected in Table 8 are then used in Eqs. (4) and (5), and with the appropriate airflow velocities the experimental tests are replicated using the Finite Difference Algorithm discussed in this work. At first, every simulation is run using the average material properties (Table 2), with the two extreme sets of discretization parameters used previously $(\Delta x=0.001 \mathrm{~m}, \Delta \mathrm{t}=3600 \mathrm{~s} ; \Delta \mathrm{x}=0.00025 \mathrm{~m}, \Delta \mathrm{t}=600 \mathrm{~s})$, and results are directly compared to the measured data. The errors in predictig the temperature distribution are calculated as the absolute value of the difference between numerical and experimental values at any time and where temperature probes are located. For every test, the corresponding errors are used to calculate their average and standard deviation, as already done in the previously. Table 9 reports the outcomes of this analysis and shows that the average errors, at both discretizations considered, are within the accuracy of calibrated termoucoples $\left(0.15^{\circ} \mathrm{C}\right)$. This is true in most cases even if the standard deviation is added. Moreover, a 
moderate improvement is achieved when the discretization is refined. If compared to the results of previous phases, this improvement might be attributed to the reduction in timestep, rather than that of the spatial grid size.

Table 9: comparison between numerical and experimental results: average temperature distribution errors and standard deviations at all the airflow velocities considered.

\begin{tabular}{lccccccc}
\hline airflow velocity $\mathrm{u}_{\mathrm{f}}$ & {$[\mathrm{m} / \mathrm{s}]$} & 0 & 0.001 & 0.003 & 0.006 & 0.009 & 0.012 \\
\hline average error $(1 \mathrm{~mm}, 3600 \mathrm{~s})$ & {$\left[{ }^{\circ} \mathrm{C}\right]$} & 0.07 & 0.08 & 0.08 & 0.10 & 0.10 & 0.10 \\
standard deviation $(1 \mathrm{~mm}, 3600 \mathrm{~s})$ & {$\left[{ }^{\circ} \mathrm{C}\right]$} & 0.04 & 0.05 & 0.05 & 0.06 & 0.07 & 0.07 \\
\hline average error $(0.25 \mathrm{~mm}, 600 \mathrm{~s})$ & {$\left[{ }^{\circ} \mathrm{C}\right]$} & 0.06 & 0.07 & 0.07 & 0.08 & 0.07 & 0.06 \\
standard deviation $(0.25 \mathrm{~mm}, 600 \mathrm{~s})$ & {$\left[{ }^{\circ} \mathrm{C}\right]$} & 0.04 & 0.05 & 0.04 & 0.05 & 0.04 & 0.04 \\
\hline
\end{tabular}
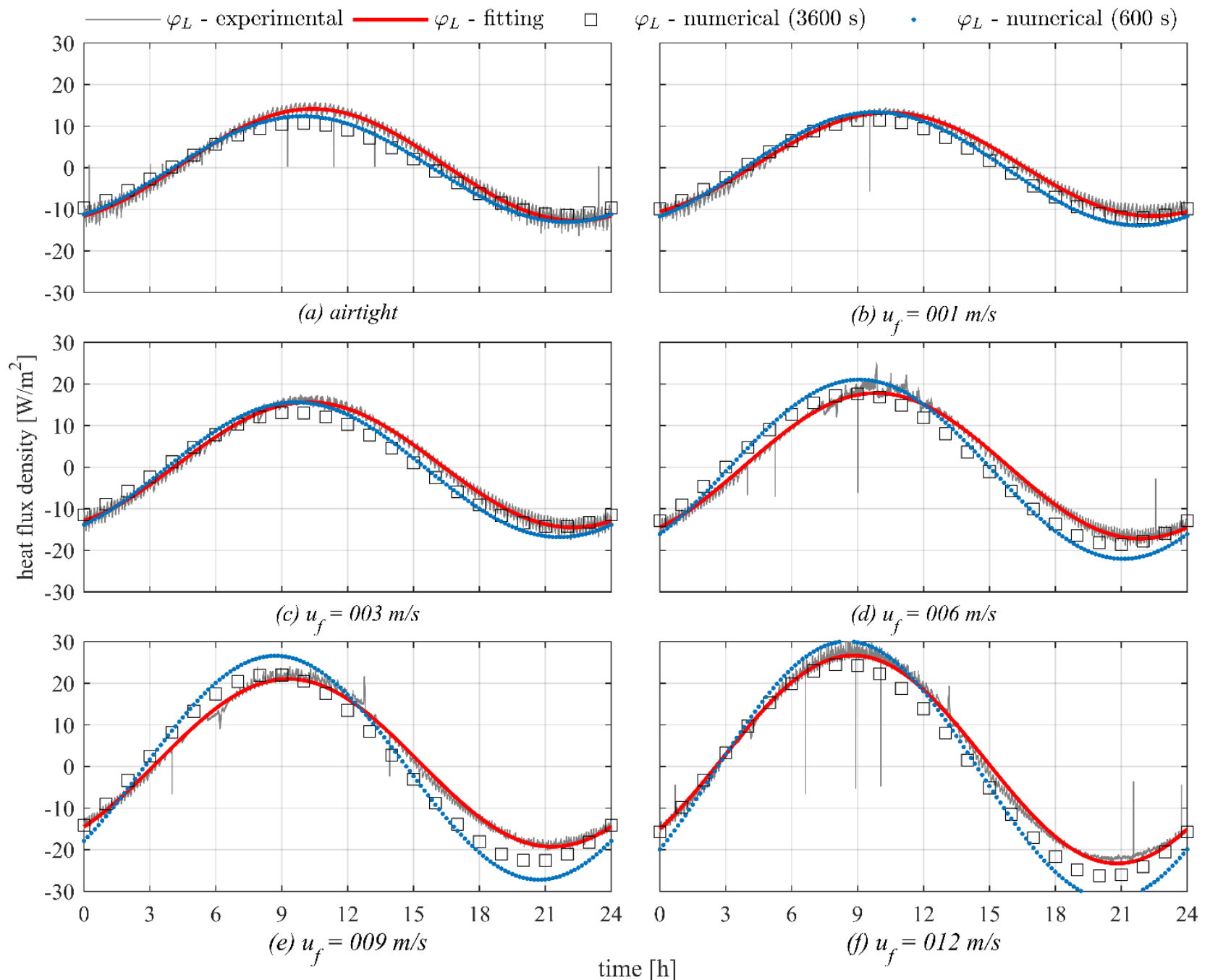

Figure 16: comparison between numerical and experimental heat flux density fluctuations at the inner face for six airflow conditions: (a) airtight, (b) $0.001 \mathrm{~m} / \mathrm{s}$, (c) 0.003 , (d) $0.006 \mathrm{~m} / \mathrm{s}$, (e) 0.009 and (f) $0.012 \mathrm{~m} / \mathrm{s}$ and two discretizations.

As far as heat flux densities are concerned, since measured values show high frequency fluctuations, a direct comparison between measured and calculated data is unpractical. Therefore, a fitting process is applied to this quantity too. The fitting equation is then:

$$
\varphi_{L}(t)=\bar{\varphi}_{L}+\Delta \varphi_{L} \cos \left(\omega t+\psi_{\varphi}\right)
$$

and the coefficients are reported in Table 10. The fluctuations calculated and measured at every airflow condition are reported in Figure 16. It is possible to observe that the agreement is acceptable until the airflow velocity is within $0.003 \mathrm{~m} / \mathrm{s}$, then the discrepancy becomes significant, even more so if the refined discretization is considered. More in detail, the discrepancies are both in terms of amplitude and phase: at higher airflow speed, the numerical fluctuation overestimates the fluctuation, if the $600 \mathrm{~s}$ data set is considered, and the stationary points in the cuirves are anticipated by $0.33-0.75 \mathrm{~h}$. 
Table 10: results of the fitting process applied on the measured heat flux densities.

\begin{tabular}{cccccccc}
\hline $\boldsymbol{u}$ & {$[\mathbf{m} / \mathbf{s}]$} & $\mathbf{0}$ & $\mathbf{0 . 0 0 1}$ & $\mathbf{0 . 0 0 3}$ & $\mathbf{0 . 0 0 6}$ & $\mathbf{0 . 0 0 9}$ & $\mathbf{0 . 0 1 2}$ \\
\hline $\bar{\varphi}_{L}$ & {$\left[\mathrm{~W} / \mathrm{m}^{2}\right]$} & -0.98 & -0.77 & -0.87 & -0.70 & -1.21 & -2.16 \\
$\Delta \varphi_{L}$ & {$\left[\mathrm{~W} / \mathrm{m}^{2}\right]$} & 13.33 & 12.49 & 14.95 & 17.45 & 20.22 & 24.98 \\
$\psi_{\varphi}$ & {$[\mathrm{rd}]$} & 0.356 & 0.413 & 0.402 & 0.493 & 0.649 & 0.773 \\
\hline
\end{tabular}

This lack of agreement at higher airflow velocity is also quantitatively confirmed in terms of average error and standard deviation, as shown in Table 11, as long as the worsening effect related to the discretization refinement. Since a refined numerical scheme should better replicate the exact solution of the heat transfer problem, as demonstrated in the first two phases of this investigation, this finding needs to be further analyzed.

Table 11: average surface heat flux density errors and standard deviations at all the airflow velocities considered.

\begin{tabular}{lccccccc}
\hline airflow velocity $u_{f}$ & {$[\mathrm{~m} / \mathrm{s}]$} & 0 & 0.001 & 0.003 & 0.006 & 0.009 & 0.012 \\
\hline average error $(1 \mathrm{~mm}, 3600 \mathrm{~s})$ & {$\left[\mathrm{W} / \mathrm{m}^{2}\right]$} & 2.03 & 1.67 & 2.12 & 2.89 & 3.12 & 2.59 \\
standard deviation $(1 \mathrm{~mm}, 3600 \mathrm{~s})$ & {$\left[\mathrm{W} / \mathrm{m}^{2}\right]$} & 1.22 & 1.13 & 1.32 & 1.55 & 1.86 & 2.04 \\
\hline average error $(0.25 \mathrm{~mm}, 600 \mathrm{~s})$ & {$\left[\mathrm{W} / \mathrm{m}^{2}\right]$} & 1.30 & 1.65 & 1.86 & 3.58 & 4.92 & 4.36 \\
standard deviation $(0.25 \mathrm{~mm}, 600 \mathrm{~s})$ & {$\left[\mathrm{W} / \mathrm{m}^{2}\right]$} & 0.93 & 1.09 & 1.21 & 1.84 & 2.53 & 2.76 \\
\hline
\end{tabular}

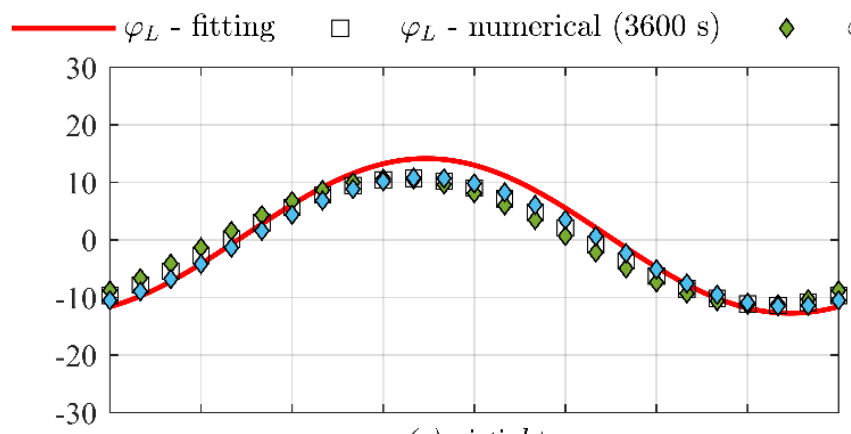

(a) airtight

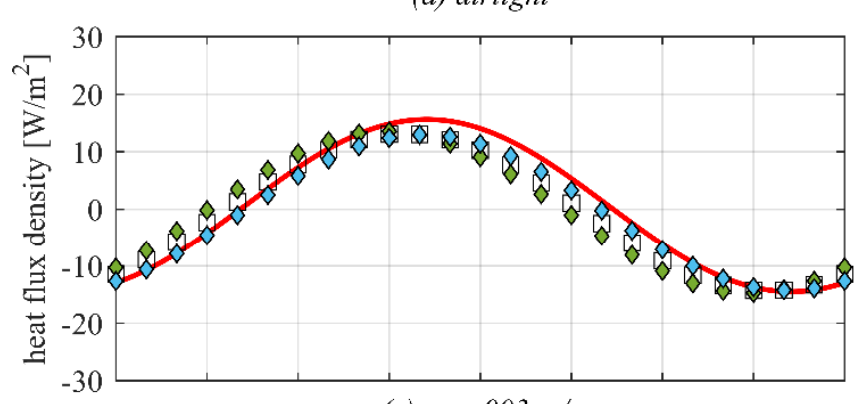

(c) $u_{f}=003 \mathrm{~m} / \mathrm{s}$
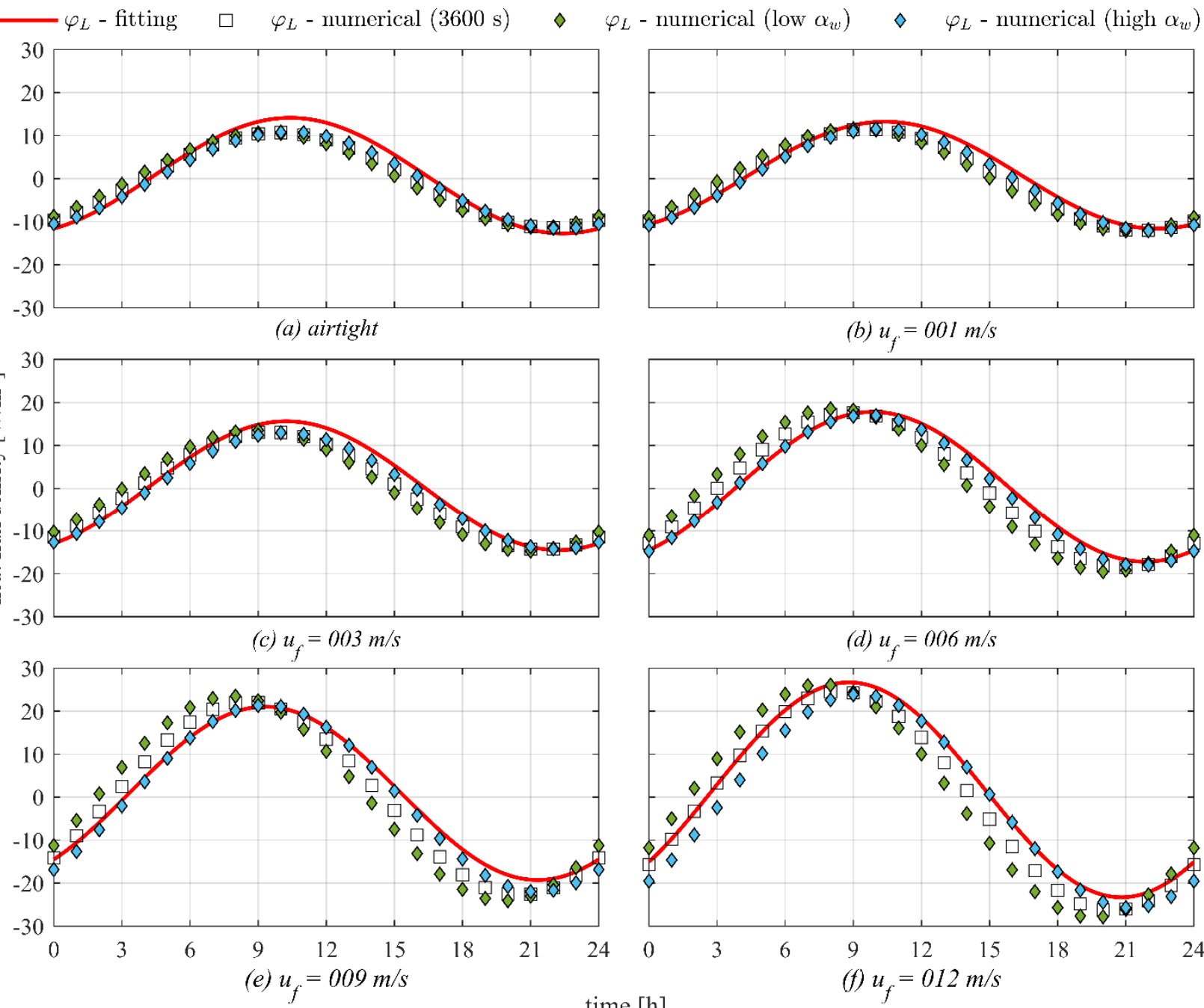

(d) $u_{f}=006 \mathrm{~m} / \mathrm{s}$

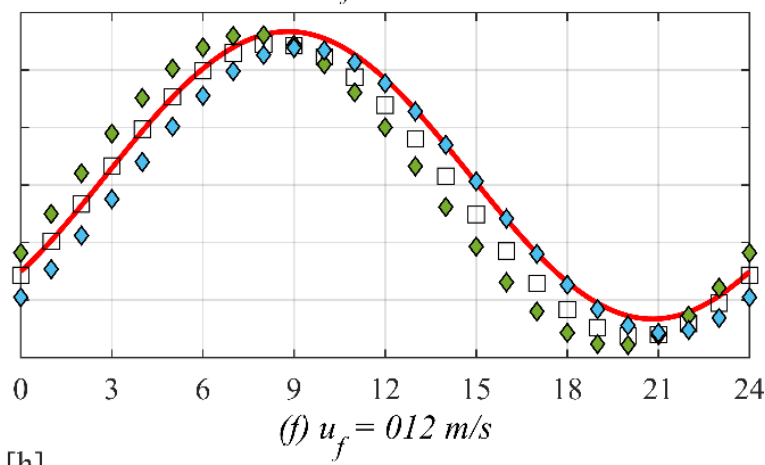

time $[\mathrm{h}]$

Figure 17: comparison between experimental heat flux density fluctuations and the corresponding numerical results, at three thermal diffusivity levels, for six airflow conditions: (a) airtight, (b) $0.001 \mathrm{~m} / \mathrm{s}$, (c) 0.003, (d) $0.006 \mathrm{~m} / \mathrm{s}$, (e) 0.009 and (f) $0.012 \mathrm{~m} / \mathrm{s}$.

At first, the offset between numerical and experimental heat flux density curves could be due to the thermalphysical properties used in the simulations: it has in fact to be remembered that the no-fines concrete 
properties reported in Table 2 are provided in ranges due to measurement uncertainty, and all the simulations previously discussed are performed considering the average values for all those quantities. In order to consider the effects of their uncertainties, all the values are combined in order to either minimize or maximize the overall thermal diffusivity as defined in (8). The values adopted in this analysis are $5.86 \cdot 10^{7} \mathrm{~m}^{2} / \mathrm{s}$ (low diffusivity) and $8.57 \cdot 10^{7} \mathrm{~m}^{2} / \mathrm{s}$ (high diffusivity). This also implies that the fluid scaled velocity, as defined in Eq.(9), is manipulated accordingly, to take into account the effects of uncertainties related to the solid domain on the advective component of the physical problem.

Table 12: average surface heat flux density errors and standard deviations at all the airflow velocities considered, as a function of the thermal diffusivity value considered during simulations. Numerical discretization: $\Delta x=1 \mathrm{~mm}$,

$$
\Delta t=3600 \mathrm{~s}
$$

\begin{tabular}{clccccccc}
\hline $\begin{array}{c}\text { thermal } \\
\text { diffusivity }\end{array}$ & \multicolumn{1}{c}{ airflow velocity $u_{f}$} & {$[\mathrm{~m} / \mathrm{s}]$} & 0 & 0.001 & 0.003 & 0.006 & 0.009 & 0.012 \\
\hline \multirow{2}{*}{ low } & average error & {$\left[\mathrm{W} / \mathrm{m}^{2}\right]$} & 2.740 & 2.606 & 3.374 & 4.939 & 5.812 & 5.599 \\
& standard deviation & {$\left[\mathrm{W} / \mathrm{m}^{2}\right]$} & 1.489 & 1.494 & 1.855 & 2.489 & 2.994 & 3.339 \\
\hline$---{ }^{*}$ high & average error & {$\left[\mathrm{W} / \mathrm{m}^{2}\right]$} & 1.563 & 1.057 & 1.241 & 0.901 & 1.342 & 2.706 \\
& standard deviation & {$\left[\mathrm{W} / \mathrm{m}^{2}\right]$} & 1.053 & 0.661 & 0.983 & 0.707 & 0.996 & 1.969 \\
\hline
\end{tabular}

Again, the results of two sets of simulations are compared to the corresponding heat flux densities calculated through the fitting process on experimental results using Eq. (32), as shown in Figure 17. Across the whole range of airflow velocity considered, it is possible to observe that the high diffusivity curve (light blue markers) provides a generally better representation of the fitted measured curve (red line). This consideration is quantitatively confirmed by the data reported in Table 12, that demonstrate how the higher thermal diffusivity provides a general reduction in both average error and standard deviation. Even though related data are not explicitly reported here, a higher than average thermal diffusivity also improves the reproduction of the temperature distribution across the domain. This observation shows how the results of the simulation process are affected by uncertainties in the material properties.

Finally, the effects of the boundary conditions uncertainties on the simulated heat flux have been evaluated. Going more in detail, the thermocouple accuracy of $0.15^{\circ} \mathrm{C}$ is either summed or subtracted to both outer and inner boundary conditions, in order to alternatively decrease or increase the almost null stationary temperature difference by $0.30^{\circ} \mathrm{C}$. The new sets of boundary conditions have then been used to run new numerical simulations and calculate the corresponding heat flux density fluctuations.

The results of this new analysis are displayed in Figure 18. In all the airflow conditions considered, it appears clear how the heat flux density is largely influenced by the definition of the thermal boundary condition: even the simple manipulation of their stationary components according to the thermocouples accuracy leads to instantaneous ranges of heat flux density fluctuations that include the fitting of the measured values in most cases.

These last two analyses demonstrate the existence of possible sources of error in a simulation, other than the choice of coarse discretization parameters, and potentially as relevant as the latter. Some general suggestions for the practical application of the numerical model to a building performance simulation can be derived from these outcomes. Indeed, it can be inferred that, due to the intrinsic uncertainties related to some parameters and inputs, such as boundary conditions and material properties, whenever a user needs results in short time (e.g.: for pre-design purposes) a coarse discretization could be acceptable. Further, it is also useful to run a set of preliminary sensitivity analyses on these factors, in order to define a range of confidence for the final results. 


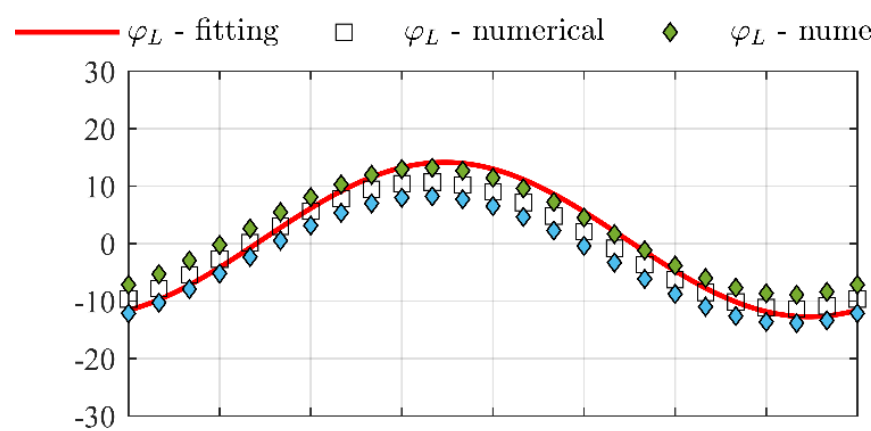

(a) airtight

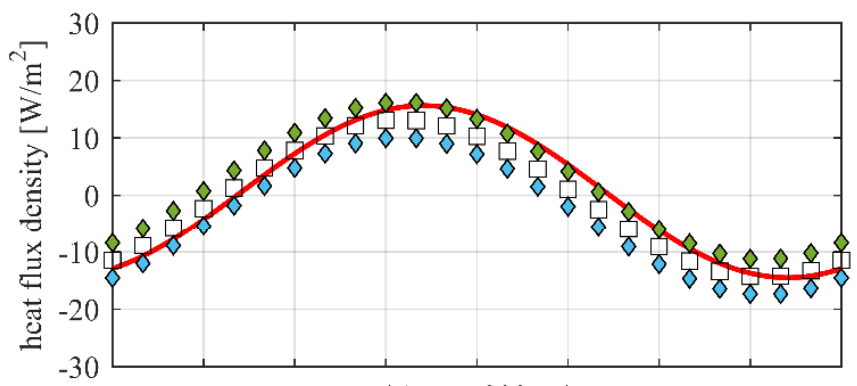

(c) $u_{f}=003 \mathrm{~m} / \mathrm{s}$

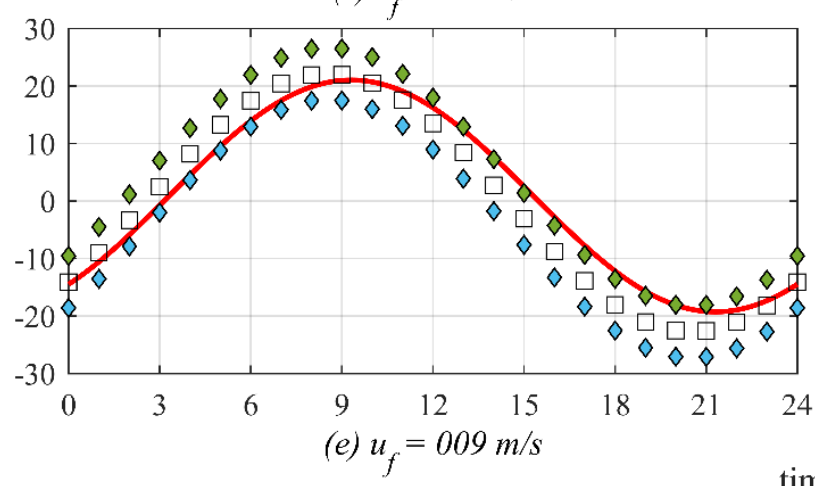

time $[\mathrm{h}]$ $\diamond \quad \varphi_{L}-$ numerical $\left(\Delta T_{s t}+0.30^{\circ} \mathrm{C}\right)$

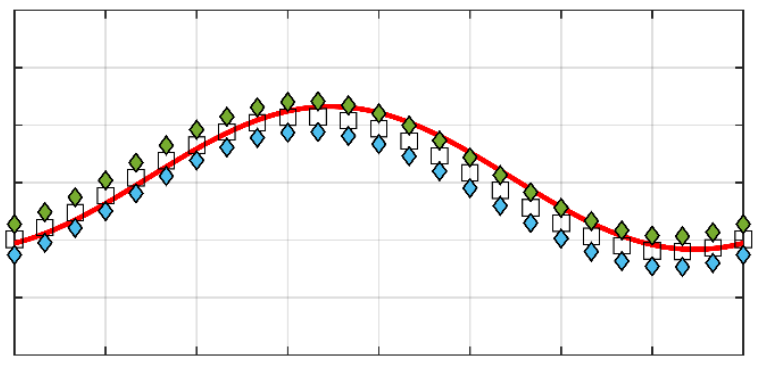

(b) $u_{f}=001 \mathrm{~m} / \mathrm{s}$

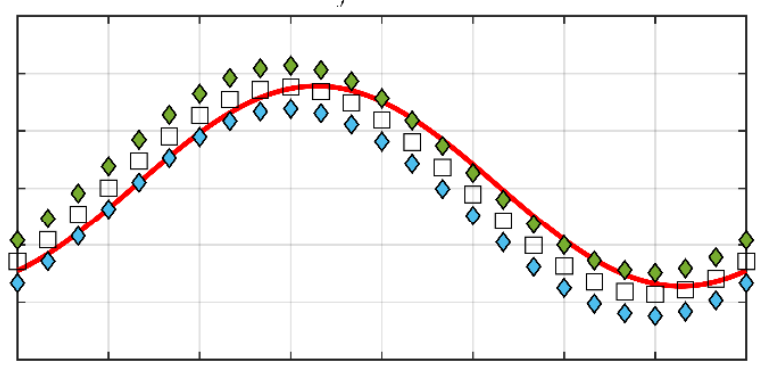

(d) $u_{f}=006 \mathrm{~m} / \mathrm{s}$

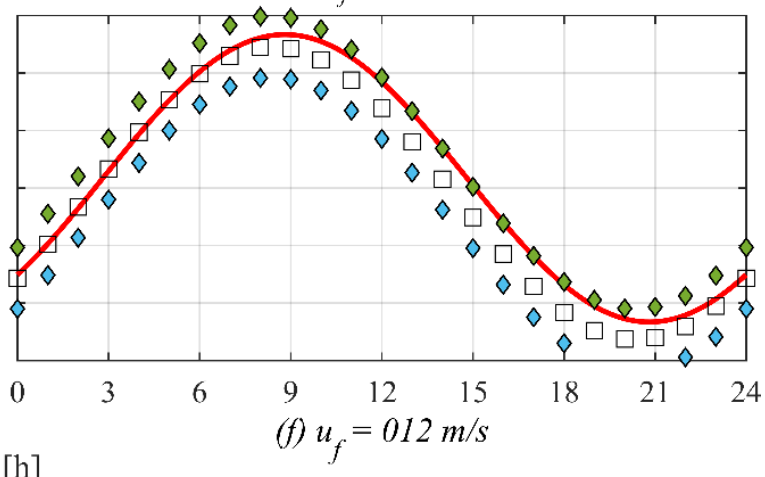

Figure 18: comparison between experimental heat flux density fluctuations and the corresponding numerical results, including the impact of the thermocouples accuracy on boundary conditions, for six airflow conditions: (a) airtight, (b) $0.001 \mathrm{~m} / \mathrm{s}$, (c) 0.003, (d) $0.006 \mathrm{~m} / \mathrm{s},(e) 0.009$ and (f) $0.012 \mathrm{~m} / \mathrm{s}$.

\section{Conclusions}

In this work, a numerical model aimed at the dynamic simulation of Breathing Wall components is presented, validated and thoroughly investigated.

The two validation steps engage the numerical model from different perspectives. Indeed:

- the simple sinusoidal outdoor condition is used to identify the sensitivity of the model to the discretization parameters, both in terms of temperature distribution and surface heat flux density, and to assess the computational cost related to them;

- the generic periodic variation, simulating a fictitious sun-air temperature profile, presents steeper variations compared to the sinusoidal variation and sudden change in direction of the derivative; the performance of the numerical model in relation to this kind of boundary condition is somehow worse, yet still acceptable; the influence of the discretization parameters is similar to the simple sinusoidal conditions case.

Moreover, the numerical model performance is evaluated in relation to materials with different behaviors: the no-fines concrete wall results in a fairly homogeneous temperature gradient along the thickness, while in the mineral wool wall the gradient concentrates close to the inside surface. 
For all these reasons, the generally good agreement found between the numerical model outputs and the analytical data can be considered a robust validation. In addition, the sensitivity analyses performed provide useful criteria for the best use of the numerical model, i.e.:

- for an accurate prediction on the temperature profile inside the porous sample, the most relevant discretization parameter is the timestep, while the effect of reducing the spatial discretization is negligible;

- at the same time, for a better prediction of the conduction heat flow density at the wall surfaces, a refinement of the space discretization below $1 \mathrm{~mm}$ has proved to be helpful; in this regard, a possible approach to achieve reliable results while containing the computational cost might be the introduction of a variable discretization grid, coarser in the centre of the domain/subdomain and with small distances between nodes in the proximity of the edges (e.g.: surfaces toward the indoor or the outdoor environments, interfaces between layers). This approach is strongly suggested whenever a resistive material its involved, due to the concentration of the temperature gradient toward the boundary. In these cases, significant improvements can also be achieved by adopting a 3-points scheme over a 2-points one to calculate the incremental ratio.

The last step of this work consists of a comparison between experimental data, collected on a no fines concrete wall subjected to sinusoidal steady periodic conditions, and numerical results. The purpose of this part of the work is to evaluate the performance of the numerical model in the context of real component simulation, considering the potential weight of uncertainties related to the material characterization. This analysis shows that numerical errors estimated in the previous validation phase may have the same significance as the uncertainties in the thermal-physical properties of the porous domain and in the boundary conditions.

It is possible to remark that the adoption of an implicit numerical scheme, intrinsically stable, offers the opportunity to adjust the space and time grids independently. Therefore, a full time and space grid sensitivity analysis can be carried out by the user in order to find the best compromise between accuracy and computational burden for the specific kind of Breathing Wall component analysed.

Finally, the set of investigations presented in this work allows to draw general conclusions applicable to numerical simulation of buildings. First of all, the optimal timestep size could be determined through a preliminary investigation of the boundary conditions, by means of frequency analysis, and should be in the order of magnitude of $1 / 10^{\text {th }}$ of the time period of the higher-frequency harmonic to be sampled. Further refinements show negligible improvement on the accuracy of the results. Secondly, if a simulation is performed for pre-design purposes, coarse discretization is acceptable, since there is still an inherent approximation due to the, generally unknown, accuracy of materials' thermophysical properties and boundary conditions definition. Moreover, a sensitivity analysis about these quantities is recommended, in order to define a confidence range for the final results. Finally, whenever an accurate estimation of the surface heat flux density is needed (e.g. when coupling with a BES tool), a 3-point scheme is preferable over the 2-point one to guarantee better accuracy, especially in the case of insulating materials.

The future development of this work will be focused on the practical use of the numerical model. More in detail, the Finite Difference numerical model of the Breathing Wall will be linked to a Building Energy Simulation tool, allowing to investigate the best strategies to integrate such technology in the building envelope and ventilation system. Furthermore, the numerical model will be expanded to include moisture transport phenomena and to take into account variable material properties. 


\section{Nomenclature}

$\begin{array}{cl}a_{w} & \text { solar absorptivity }[-] \\ c & \text { specific thermal capacity }[\mathrm{J} /(\mathrm{kg} \cdot \mathrm{K})] \\ C_{B W} & \text { effective thermal conductance }\left[\mathrm{W} /\left(\mathrm{m}^{2} \cdot \mathrm{K}\right)\right] \\ e & \text { error }\left[{ }^{\circ} \mathrm{C}\right] /\left[\mathrm{W} / \mathrm{m}^{2}\right] \\ h_{c r, e x t} & \text { external convective-radiative surface heat } \\ & \text { transfer coefficient }\left[\mathrm{W} /\left(\mathrm{m}^{2} \cdot \mathrm{K}\right)\right] \\ \mathfrak{J} & \text { imaginary part of a complex number }[-] \\ i & \text { space node index }[-] / \text { imaginary unit }[-] \\ j & \text { time node index }[-] \\ K & \text { order of the steady periodic component }[-] \\ L & \text { size of the sample/domain }[\mathrm{m}] \\ M & \text { maximum time node index }[-] \\ N & \text { maximum space node index }[-] \\ P e & \text { Péclet number }[-] \\ \Re & \text { real part of a complex number }[-] \\ R_{c d} & \text { conductive thermal resistance }\left[\mathrm{m}^{2} \cdot \mathrm{K} / \mathrm{W}\right] \\ T & \text { temperature }\left[{ }^{\circ} \mathrm{C}\right] \\ t & \text { time coordinate }[\mathrm{s}] \\ u & \text { airflow velocity }[\mathrm{m} / \mathrm{s}] \\ x & \text { space coordinate }[\mathrm{m}] \\ & \end{array}$

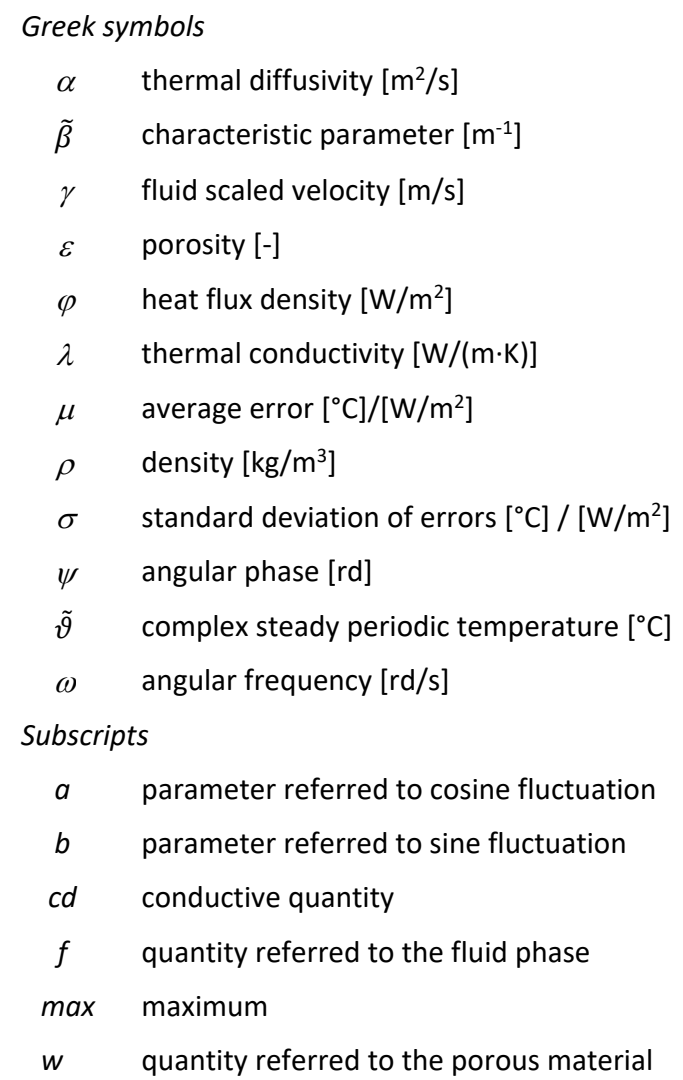

\section{References}

Alongi A., Mazzarella L. (2015). Characterization of fibrous insulating materials in their application in dynamic insulation technology. Energy Procedia (78) 537-542

Alongi A., Mazzarella L. (2015). The Dual Air Vented Thermal Box: a laboratory apparatus to test air permeable building envelope technologies. Energy Procedia (78), 1543-1548.

Alongi A., Angelotti A., Mazzarella L. (2017a). Experimental investigation of the steady state behaviour of Breathing Walls by means of a novel laboratory apparatus. Building and Environment (123), 415-426.

Alongi A., Angelotti A., Mazzarella L. (2017b). Analytical modelling of Breathing Walls: experimental verification by means of the Dual Air Vented Thermal Box lab facility. Energy Procedia (140), 36-47.

Alongi A., Angelotti A., Mazzarella L. (2019). Measuring a Breathing Wall's effectiveness and dynamic behaviour. Indoor and Built Environment, DOI: 10.1177/1420326X19836457

Alongi A., Angelotti A., Mazzarella L. (2020). Experimental validation of a steady periodic analytical model for Breathing Walls. Building and Environment (168), https://doi.org/10.1016/j.buildenv.2019.106509.

Ascione F., Bianco N., De Stasio C., Mauro G.M., Vanoli G.P. (2015). Dynamic insulation of the building envelope: numerical modeling under transient conditions and coupling with nocturnal free cooling, Applied Thermal Engineering (84), 1-14.

Ascione F. (2017), Energy conservation and renewable technologies for buildings to face the impact of the climate change and minimize the use of cooling, Sol. Energy (154),34-100. http://dx.doi.org/10.1016/j.solener.2017.01.022

Baker P.H. (2003). The thermal performance of a prototype dynamically insulated wall. Building Services Engineering Research and Technology (24), 25-34. doi:10.1191/0143624403bt057oa

Brunsell J.T. (1996). The performance of dynamic insulation in two residential buildings. Air Infiltration Review (16), 711.

Craig S. and Grinham J. (2017). Breathing walls: The design of porous materials for heat exchange and decentralized ventilation. Energy and Buildings (149), 246-259.

Di Giuseppe E., D’Orazio M., Di Perna C. (2015). Thermal and filtration performance assessment of a dynamic insulation system. Energy Procedia (78), 513-518.

Dimoudi A., Androutsopoulos A., Lykoudis S. (2004). Experimental work on a linked, dynamic and ventilated wall component. Energy and Building (36), 443-453. 
Elsarrag E., Al-Horr Y., Imbabi M.S. (2012). Improving building fabric energy efficiency in hot-humid climates using dynamic insulation. Building Simulation (5), 127-134. doi:10.1007/s12273-012-0067-6

Ente Italiano di Normazione, Riscaldamento e raffrescamento degli edifici - Dati climatici - Parte 2: Dati di progetto. UNI/TR 10349-2:2016

Gan G. (2000). Numerical evaluation of thermal comfort in rooms with dynamic insulation. Building and Environment (35), 445- 453.

Gradeci K., Berardi U., Time B., Köhler J. (2018), Evaluating highly insulated walls to withstand biodeterioration: A probabilistic-based methodology. Energy and Buildings (177), 112-124. doi.org/10.1016/j.enbuild.2018.07.059

Imbabi M.S. (2004). New developments in the science and art of Breathing Walls. Proceedings from WREC 2004: World Renewable Energy Congress VIII. Denver (CO), 1-8 September 2004.

Imbabi M.S. (2006). Modular breathing panels for energy efficient, healthy building construction. Renewable Energy (31), 729-738.

Imbabi, M. S., Brown, A. R., Peacock, A., \& Murphy, J. (2008). The transforming technology of dynamic breathing building. In Ecocity World Summit San Francisco USA, 1-12.

Imbabi M.S. (2012). A passive-active dynamic insulation system for all climates. International Journal of Sustainable Built Environment (1), 247-258.

Kalagasidis A. S., Rode C., Woloszyn M. (2008). HAM-Tools - a whole building simulation tool in Annex 41. In C. Rode, H. Hens, \& H. Janssen (Eds.), Proceedings of the IEA ECBCS Annex 41 Closing Seminar (pp. 21- 35). Technical University of Denmark, Department of Civil Engineering.

Kaviany M. (1995). Principle of Heat Transfer in Porous Media - second edition. Springer New York

Krarti M. (1994). Effect of air flow on heat transfer in walls. Journal of Solar Energy Engineering (116), 35-42.

Park B., Srubar W.V., Krarti M. (2015). Energy performance analysis of variable thermal resistance envelopes in residential buildings. Energy and Buildings (103), 317-325. https://doi.org/10.1016/j.enbuild.2015.06.061

Rupp S., Krarti M. (2019). Analysis of multi-step control strategies for dynamic insulation systems. Energy and Buildings (204) 109459.

Samuel A., Imbabi M.S., Peacock A., Strachan, P.A., (2003) An engineering approach to modelling of dynamic insulation using ESP-r. In: Proceedings of the Worldwide CIBSE/ASHRAE Building Sustainability, Value and Profit Conference. Chartered Institute of Building Service Engineers (CIBSE).

Steeman M., Janssens A., Steeman H.J., Van Belleghem M., De Paepe M. (2010). On coupling 1D non-isothermal heat and mass transfer in porous materials with a multizone building energy simulation model. Building and Environment (45), 865-877. doi:10.1016/j.buildenv.2009.09.006

Taylor B.J., Cawthorne D.A., Imbabi M.S. (1996). Analytical investigation of the steady-state behaviour of dynamic and diffusive building envelopes. Building and Environment (31), 519-525.

Taylor B.J. and Imbabi M.S. (1998). The application of dynamic insulation in buildings. Renewable Energy (15), $377-382$.

Taylor B.J., Webster R., Imbabi M.S. (1999). The building envelope as an air filter. Building and Environment (34), 353361.

Wallenten P. (1995), Analytical and numerical analysis of dynamic insulation, in: Proceedings of the Building Simulation 1995, Session 7a: Heat Transfer, pp. 555-562.

Wang J., Du Q., Zhang C., Xu X., Gang W. (2018). Mechanism and preliminary performance analysis of exhaust air insulation for building envelope wall. Energy \& Buildings (173) 516-529.

Wong J.M., Glasser F.P., Imbabi M.S. (2007), Evaluation of thermal conductivity in air permeable concrete for dynamic breathing wall construction. Cement \& Concrete Composites (29) 647-655.

Yaegashi A., Hiyama K., Kato S., Tezuka J., Nikawa S., (2015). Thermal Performance Evaluation of a Dynamic Insulation Technology Applied to a Timber Framework House in a Real Environment. Journal of Asian Architecture and Building Engineering (14), 213-218.

Zheng C. and Bennett G.D. (2002). Applied Contaminant Transport Modeling, John Wiley \& Sons, 2nd Edition. 